\title{
VI. Die Ausgestaltung des Vertrages: Gegenleistungen für den nuklearen Verzicht der Nichtkernwaffenstaaten?
}

Die Achtzehn-Mächte-Abrüstungskonferenz in Genf wurde nicht nur von der Konfrontation zwischen den Supermächten und ihren Machtblöcken beherrscht. Während der Verhandlungen um den Nichtverbreitungsvertrag bildete sich eine weitere Frontstellung, die den Ost-West Gegensatz überlagerte. Die Scheidelinie verlief zwischen den Kernwaffenstaaten und den Nichtkernwaffenstaaten. ${ }^{1}$ Im Gegensatz zum Teststopp-Abkommen, bei dem sich alle Teilnehmerstaaten zu einem Verzicht auf Tests - unterirdische Tests ausgenommen - verpflichtet hatten, wurde nun eine einseitige Verzichtserklärung erwartet. Die Nichtkernwaffenstaaten fürchteten, die Supermächte könnten über ihre Köpfe hinweg ein fait accompli schaffen, das die Interessen der Staaten, die keine Kernwaffen besaßen, überging. Sie fragten im Lauf der Verhandlungen immer lauter nach den Gegenleistungen für den einseitigen Verzicht.

Die Forderungen der Nichtkernwaffenstaaten bezogen sich auf die mit dem Nichtverbreitungsvertrag zu verbindenden nuklearen Abrüstungsmaßnahmen, die Möglichkeiten der Nichtkernwaffenstaaten auf dem Gebiet der friedlichen Nutzung der Kernenergie, ihren Schutz gegen nukleare Erpressung und Bedrohung und die Überwachung des Vertrags durch ein Kontrollsystem. Diese Forderungen bargen ein hohes Konfliktpotential; andererseits war ein Kompromiß mit einer Mehrheit der Nichtkernwaffenstaaten unerläßlich, hing doch der Erfolg des NPT hauptsächlich von der Unterzeichnung bestimmter Schwellenländer ab. Ein Abkommen ohne die deutsche Unterschrift war ebenso wertlos, wie die Teilnahme Indiens, Israels oder Japans von zentraler Bedeutung für die globale Anerkennung des NPT war. In Genf wurde ein aktiver Vermittler zwischen den Nichtkernwaffenstaaten und den beiden nuklearen Riesen gebraucht. Großbritannien befand sich zwischen diesen beiden Lagern und schien damit für diese Rolle besonders geeignet. Inwieweit es sie ausfüllen konnte, soll im folgenden näher beleuchtet werden.

\footnotetext{
${ }^{1}$ Bourantonis spricht von den NPT-Verhandlungen als einen „two step process“ mit den Verhandlungen der Supermächte als erste Phase und den Verhandlungen mit den Nichnuklearen als zweite Phase. Unzutreffend ist jedoch die Frontstellung, die Bourantonis für die zweite Phase der Verhandlungen annimmt: "The second stage involved similar methods but this time between the two superpowers supported by their allies on the one hand and the NNWS which were mostly identified with the Non-Aligned states on the other hand." Bourantonis, United Nations, S. 83. Es wird sich zeigen, daß die Forderungen der nichtnuklearen Verbündeten der USA nicht weniger Konfliktpotential bargen als die Interessen der blockfreien Staaten.
} 


\section{Sicherheitsgarantien für die Nichtkernwaffenstaaten? Sonderfall Indien}

\section{Vorschläge der Atommächte zum Schutz der Nichtkernwaffenstaaten}

Die Frage der Sicherheitsgarantien entstand mit der Zündung der ersten chinesischen Bombe und der Befürchtung der Atommächte, Indien würde dem chinesischen Beispiel folgen. In Delhi wurde die chinesische Bombe als direkte Bedrohung angesehen. Indien hatte im chinesisch-indischen Grenzkonflikt von 1962 eine Niederlage erlitten und fürchtete nun, China werde in Zukunft seine Interessen auf dem asiatischen Subkontinent mittels nuklearer Erpressung verfolgen. Indien konnte als blockfreier Staat nicht auf den Schutz durch eine Supermacht vertrauen. Dazu kamen die Spannungen zwischen Indien und seinem Nachbar Pakistan. Durch den indisch-pakistanischen Grenzkrieg im Sommer 1965 wurden die indischen Befürchtungen verstärkt. China drohte während dieser Auseinandersetzung mit der Eröffnung einer zweiten Front. Daraufhin mehrten sich in Indien die Stimmen, die nun ein eigenes Atomprogramm forderten. Sicherheitsgarantien hatten auch im Nahen Osten eine besondere Bedeutung. Israel fürchtete künftige Atomprogramme der arabischen Staaten. Die Araber wiederum bezichtigten Israel solcher Vorhaben. Gleichwohl war die Lösung des indischen Problems von vorrangiger Bedeutung. Die indische Teilnahme oder Nichtteilnahme hatte Signalwirkung auf viele andere Nichtkernwaffenstaaten. Indien galt als die potentielle sechste Atommacht. Sollte sich Delhi die nukleare Option offenhalten, würden viele Staaten, insbesondere im asiatischen Raum, dem indischen Beispiel folgen. Indien hatte daher eine Schlüsselposition nicht nur hinsichtlich der nuklearen Bedrohung, sondern vor allem auch als Vorbild für andere Schwellenländer. Großbritannien alleine konnte den Indern keine überzeugenden Sicherheitgarantien geben. Nur die Supermächte waren in der Lage, Indien glaubhaften nuklearen Schutz zu bieten.

Unmittelbar nach dem ersten chinesischen Atomtest im Oktober 1964 versprach der amerikanische Präsident Johnson allen Nichtkernwaffenstaaten Schutz vor nuklearer Bedrohung. ${ }^{2}$ Diese Zusage war allgemein formuliert, bezog sich jedoch direkt auf Indien. Als Irland im Januar 1965 in der Vollversammlung der Vereinten Nationen im Auftrag der USA eine Resolution vorlegte, die den baldigen Abschluß eines Nichtverbreitungsabkommens forderte, um einer gegen die MLF gerichteten Resolution zuvorzukommen, ließ die amerikanische Regierung jedoch die Passagen, die sich auf Sicherheitsgarantien bezogen, aus dem irischen Entwurf streichen. ${ }^{3}$ Trotz Johnsons Versprechungen scheute man in Washington davor zurück, frühzeitig bindende Verpflichtungen einzugehen. Wie der Schutz für die Staaten, die bereit waren, auf Kernwaffenbesitz zu verzichten, konkret aussehen sollte, war somit zunächst völlig unklar.

Der Gilpatric-Report empfahl, der Regierung in Delhi im Austausch gegen eine nukleare Verzichtserklärung formelle Schutzgarantien anzubieten, aber zunächst schätzte

\footnotetext{
${ }^{2}$ Seaborg, Tide, S. 115.

${ }^{3}$ Der irische Text war sowohl in Washington als auch in London Korrektur gelesen worden. Auch die britische Regierung war dafür, Hinweise auf mögliche Sicherheitsgarantien aus der Resolution zu streichen. NA, RG 59, CFPF, DEF 18, box 1593, Memo of Conversation between Mr. Faber (First Secretary, Brit. Embassy) and Mr. Freud (ACDA), 04. 01. 1965.
} 
man in Washington die Wahrscheinlichkeit eines indischen Kernwaffenprogramms gering ein. ${ }^{4}$ Indien hatte nach dem chinesischen Test versichert, es würde auch weiterhin keine eigenen Kernwaffen anstreben. Die indische Regierung hatte sich in den Genfer Verhandlungen nachhaltig für den Abschluß eines NPT und für nukleare Abrüstung eingesetzt. Es stellte sich auch die Frage, ob Indien als blockfreier Staat ein einseitiges amerikanisches Angebot überhaupt akzeptieren würde. Der amerikanische Botschafter in Indien, Bowles, riet dringend, zunächst das Engagement Indiens für ein Nichtverbreitungsabkommen in den Vereinten Nationen zu unterstützen, um der Regierung so internationales Prestige und Ansehen zu sichern und die gemäßigten Kräfte in Delhi zu stärken. Als die US-Regierung Anfang 1965 in Zusammenarbeit mit Irland die oben erwähnte Resolution in der Vollversammlung der Vereinten Nationen vorlegen wollte, wurde überlegt, Indien in die Ausarbeitung und die offizielle Präsentation mit einzubeziehen. Die Johnson-Regierung bat die Iren, Indien die Resolution mit Unterstützung der gesamten westlichen Welt einbringen zu lassen. ${ }^{5}$ In Großbritannien folgte Verteidigungsminister Healey dem Vorbild Johnsons und forderte im Unterhaus, daß alle Atommächte den Nichtkernwaffenstaaten Garantien gegen nukleare Erpressungen oder gegen Angriffe geben sollten. Falls sich die Sowjetunion weigere, sollten die westlichen Atommächte dies einseitig tun. ${ }^{6}$ Im Foreign Office sah man ebenfalls die Notwendigkeit für Sicherheitsgarantien. Diese sollten jedoch keinesfalls in direkten Zusammenhang mit einem Abkommen über Nichtverbreitung gebracht werden. Die Verhandlungen über Sicherheitsgarantien würden sich sehr schwierig gestalten und den Abschluß des NV-Vertrags nur verzögern. Dies sollte unbedingt vermieden werden. ${ }^{7}$

Im Dezember trafen sich der britische Premier Wilson und sein indischer Amtskollege Shastri zu Gesprächen. Dabei stand auch der chinesische Atomtest auf der Tagesordnung. Shastri fragte aber in diesem Zusammenhang gar nicht nach Sicherheitsgarantien, sondern bat um eine genaue Auskunft über Kosten und Umfang des britischen Atom-

${ }^{4}$ LBJL, NSF, Committee File, box 5, Committee on Non-Proliferation, A Report to the President by the Committee on Nuclear Proliferation, January 1965. Ein ACDA-Memorandum zur Frage der Sicherheitsgarantien wies darauf hin, daß Sicherheitsgarantien im Falle von Indien, jedoch auch Schweden, Israel und Japan notwendig seien, stellte aber zugleich fest, daß es äußerst schwierig werden würde, einen Weg zu finden, den Ansprüchen dieser Staaten gerecht zu werden. Die USA könnten schließlich den Nichtkernwaffenländern im Falle eines Angriffs keine automatische nukleare Vergeltung garantieren, was diese sicher als den optimalen Schutz betrachten würden. Damit gäbe die amerikanische Regierung jedoch die Kontrolle über den Einsatz ihrer Kernwaffen aus der Hand. LBJL, NSF, Committee File, box 1/2, Committee on Non-Proliferation, Memo by G. Bunn (ACDA): Security Guarantees and Non-Proliferation of Nuclear Weapons, 28. 12. 1964. Demgegenüber vertrat ein Memorandum des State Departments die Ansicht, die Versicherung Johnsons vom Oktober 1964, den Nichtkernwaffenstaaten Schutz zu gewähren, sei ausreichend, um Indien vom Bau der Bombe abzuhalten. NSA, MC, Doc. Nr. 1079, Background Paper: Factors Which Could Influence National Decisions Concerning Acquisition of Nuclear Weapons, 12.12. 1964.

${ }^{5}$ LBJL, NSF, Committee File, box 6/7, Committee on Non-Proliferation, Bowles (US-Embassy, Delhi) to Rusk and Bundy, 16. 01. 1965. Indien und die USA konnten sich nicht auf eine für beide Seiten akzeptable Formulierung einigen, deshalb brachte schließlich doch Irland im Auftrag der USA die Resolution ein.

${ }^{6}$ HC Debs., Vol. 704, c. 614, 17. 12. 1964.

${ }^{7}$ PRO, FO 371/181386, Memo by Mr. Street (FO), 23. 12. 1964. Diese Position wurde in der folgenden Zeit mehrfach und nachdrücklich bestätigt. 
programms. Wilson sandte Shastri eine Studie des britischen Verteidigungsministeriums über den geschätzten Kostenaufwand für ein indisches Atomprogramm ${ }^{8}$ und betonte in einem Begleitschreiben die finanziellen Lasten und fand mahnende Worte hinsichtlich des nichtnuklearen Status Indiens: „The paper which I am enclosing does, however, underline the problems and the potential cost to India of embarking upon a nuclear programme which would provide a really effective deterrent against anything the Chinese could produce. This question of cost must, I am sure, be particularly in your minds... I also suggest that continuing restraint by India on this issue would be a gesture of world importance and very much in the interests of world peace. ${ }^{" 9}$ Nach dem Besuch Shastris war damit offensichtlich, daß Indien bereits mit einem nationalen Atomprogramm liebäugelte und diese Option - wenn überhaupt - nur gegen entsprechende Gegenleistungen aufgeben würde.

Der amerikanische Außenminister Rusk kam im März 1965 nach London, um das Problem mit seinem britischen Amtskollegen zu erörtern. Die Vereinigten Staaten suchten in dieser Frage die Zusammenarbeit mit Großbritannien, da man in Washington hoffte, Großbritannien könnte als Führungsnation des Commonwealth Einfluß auf Indien nehmen. Rusk erklärte gegenüber Stewart, er sehe in einem Nichtverbreitungsabkommen als unmittelbare Maßnahme wenig Sinn, da Indien damit nicht geholfen sei und die Nuklearmächte ohnehin nicht weiterverbreiten würden. Er behauptete, die USA hätten in bezug auf Israel und Japan weniger Bedenken. Die USA seien in der Lage, mögliche nukleare Ambitionen dieser Länder individuell in den Griff zu bekommen. Rusk bekannte jedoch, daß Indien ein Problem darstelle, da die USA keine bindenden Sicherheitserklärungen abgeben wollten. Rusk fragte seinen Amtskollegen Stewart schließlich, ob an eine Pacific Nuclear Force zu denken sei. ${ }^{10}$ Tatsächlich gab es bereits Überlegungen dieser Art. Nachdem der indische Premier nachhaltiges Interesse an einem Atomprogramm bekundet hatte, dachte man in London, eine nukleare Beteiligung Indiens an einer pazifischen Atomstreitmacht könne die nuklearen Interessen Indiens befriedigen. Diese Idee barg jedoch neben dem Problem Pakistan ganz ähnliche Probleme wie die MLF/ANF in Europa: „We could hardly think in terms of nuclear protection for India

${ }^{8}$ "It is significant that during his recent visit to London Mr Shastri informed British Ministers in the strictest confidence that his Government was in fact looking into the costs and technical complexities of undertaking at least a nuclear weapon test and asked for information about costs based on British experience." PRO, FO 371/181434, FO-Memo, 30. 12. 1964. In einem Schreiben an das Verteidigungsministerium, das die Kostenaufstellung erarbeiten soll, wird die Episode folgendermaßen geschildert: „At the end ... the PM and the Indian PM Mr Shastri had a private talk. Mr Shastri told the PM that he was coming under increasing pressure for India to acquire a nuclear capability. He was resisting this pressure to the best of his ability, but voices were being raised to say that nuclear defence could lead to a saving in overall defence costs. The PM said that ... it was not merely a question of constructing a nuclear bomb, the question of delivery systems was far more complicated and expensive. It was an illusion to think that nuclear defence was defence on the cheap. If Mr Shastri so desired, arrangements could be made for him to be supplied on a very confidential basis with a note on this question. $\mathrm{Mr}$ Shastri welcomed this offer." PRO, PREM 13/973, Sir O. Wright to Mr Hockaday, 04. 12. 1964. Die Unterredung ist im offiziellen Gesprächsprotokoll nicht enthalten. Glaubwürdiger erscheint jedoch die interne Variante des Foreign Office, da sich Wilson unmittelbar nach dem Treffen mit Shastri äußerst besorgt über ein indisches Atomprogramm zeigte. Siehe hierzu: Ovendale, Defence Policy, S. 132.

${ }^{9}$ PRO, FO 371/176428, Wilson to Shastri, Dezember 1964, ohne genaues Datum.

${ }^{10}$ PRO, FO 371/181355, Record of Conversation, 22. 03. 1965. 
without somehow bringing in Pakistan as well. The question is, whether India would be satisfied with taking part in some control body or whether she would also want to have a share in the ownership of nuclear weapons on the same basis as is proposed for Germany in the ANF. One would hope that the Indian ambitions for a share in the ownership of nuclear weapons have not yet been aroused as much as the German and that it would be possible to confine her participation to some kind of control system. This, however, at once raises all the vexed questions of vetoes and so on. In any case, it would presumably be essential to combine any such scheme with a non-acquisition agreement, at any rate, for the countries taking part in it." ${ }^{11}$ Das britische Außenministerium ging zunächst von einer Art pazifischen nuklearen Planungsgruppe aus. Außenminister Stewart dachte eher an eine Pacific Nuclear Force ohne amerikanische Beteiligung oder ,Commonwealth-ANF', wie er es nannte. Der Außenminister hatte vor allem Bedenken, über eine multilaterale Atomstreitmacht in Asien, an der die Vereinigten Staaten beteiligt waren, in die amerikanische Vietnam- und Taiwan-Politik hineingezogen zu werden. Außerdem wäre Großbritannien im Vergleich zu den USA in einer solchen Streitmacht unterrepräsentiert gewesen. ${ }^{12}$ Eine asiatische Atomstreitmacht war zum gegenwärtigen Zeitpunkt noch nicht durchführbar, darüber war man sich in Washington und London einig. ${ }^{13}$ Außerdem hatte sich die indische Regierung in den internationalen Gremien gegen die europäische MLF und ein nuclear-sharing innerhalb der NATO ausgesprochen. ${ }^{14}$ Die Pläne blieben jedoch aktuell. Insbesondere Premierminister Wilson sah die Zukunft der britischen Atomstreitmacht in einer, Commonwealth-ANF', nachdem die britische Regierung beschlossen hatte, das ursprüngliche ANF-Konzept ganz aufzugeben. ${ }^{15}$

Nuclear-sharing im Pazifik war eine vage Option für die Zukunft, wirtschaftlicher Druck auf Indien war als Maßnahme, die indische Regierung von einem nuklearen Weg abzuhalten, nicht geeignet. ${ }^{16}$ Bindende Sicherheitsgarantien hätten den Nichtkernwaffenstaaten ein erhebliches $\mathrm{Maß}$ an Einfluß und Macht über die Atomwaffen der $\mathrm{Nu}$ klearmächte gegeben, was für die Kernwaffenstaaten einer Aufgabe der nationalen Kontrolle über ihre Arsenale gleichgekommen wäre. Damit herrschte ein halbes Jahr nach Johnsons Versicherung, allen Nichtkernwaffenstaaten Schutz vor nuklearer Bedrohung zu gewähren, immer noch Ratlosigkeit, wie dieser Schutz aussehen könnte. Im State Department suchte man nun nach einem Weg, diesen Staaten ein Mindestmaß an Sicherheit zu gewährleisten, ohne den Kernwaffenstaaten definitive Zusagen über nukleare

${ }^{11}$ PRO, FO 371/181386, Memo by Mr. Barnes (FO), 16. 12. 1964.

12 PRO, PREM 13/225, Memo by the Foreign Secretary, 26. 03. 1965.

${ }^{13}$ Ein gemeinschaftliches Memorandum des MOD, des FO und CRO zur Frage der Sicherheitsgarantien für Indien angesichts der Bedrohung durch China fand uneingeschränkte Zustimmung in Washington. PRO, FO 371/181401, Memo by the FO, the MOD and the CRO: The Problem of Safeguards for India Against a Chinese Nuclear Threat, März 1965, ohne genaues Datum. LBJL, NSF Country File: UK, box 208, US Comments on the UK Paper, ohne genaues Datum.

${ }^{14}$ PRO, FO 371/181386, Brit. Embassy, New Delhi, to CRO, 07.01. 1965.

${ }^{15}$ Siehe hierzu auch unten S. 160.

${ }^{16}$ Diese Möglichkeit wurde in London und Washington diskutiert, aber umgehend verworfen. PRO, FO 371/181401, Memo by the FO, the MOD and the CRO: The Problem of Safeguards for India Against a Chinese Nuclear Threat, März 1965, ohne genaues Datur. LBJL, NSF Country File: UK, box 208, US Comments on the UK Paper, The Problem of Safeguards for India Against a Chinese Nuclear Threat', ohne Datum. 
Beistandsverpflichtungen abzuverlangen. Man wollte eine Lösung finden, an der sich auch die Sowjetunion beteiligen konnte und die sich zugleich nicht direkt gegen China richtete. Außenminister Rusk schlug dem amerikanischen Botschafter in Delhi vor, eine multilaterale Sicherheitsgarantie der internationalen Staatengemeinschaft für alle Nichtkernwaffenstaaten in Form einer Resolution der Vereinten Nationen abzugeben. Eine Resolution der Vereinten Nationen, die ein blockfreier Nichtkernwaffenstaat einbringen könne, hatte Rusk zufolge mehrere Vorteile: Moskau müsse sich nicht zwischen Peking und Delhi entscheiden; die Staaten, die auf Atomwaffen verzichteten, hätten nicht nur einseitige Garantien, und China werde nach der Verabschiedung einer derartigen Resolution vor einer nuklearen Aggression zurückschrecken. ${ }^{17}$ Rusk hatte folgenden Entwurf vorgesehen: "The General Assembly ... welcomes the intention signified by Member States approving this resolution that they will provide or support immediate assistance to any State not possessing nuclear weapons that is the victim of an act of aggression in which nuclear weapons are used, and calls upon all other States to associate themselves with the objectives of this resolution. " 18 Mit dieser Formulierung wären die Kernwaffenstaaten zu keiner konkreten Hilfeleistung, wie etwa nuklearer Vergeltung, verpflichtet gewesen. „Act of aggression“ war zudem ein dehnbarer Begriff und ein Eingreifen der Kernwaffenstaaten konnte damit nicht automatisch eingefordert werden.

Dieser Plan wurde zunächst der indischen Regierung unterbreitet. Der indische Premierminister Shastri sollte den Vorschlag bei seinem Besuch in Moskau der Kreml-Führung präsentieren und die Chancen für eine sowjetische Beteiligung abklären. Außer der Regierung in Delhi wurde nur die britische Regierung informiert. Die Briten waren grundsätzlich einverstanden, brachten jedoch noch einen Änderungsvorschlag ein. Die Garantien sollten sich nur auf die Nichtkernwaffenstaaten erstrecken, die sich tatsächlich $\mathrm{zu}$ einem nuklearen Verzicht verpflichteten. ${ }^{19}$ Indien fand jedoch keine Unterstützung in Moskau und wollte die amerikanische Initiative damit auch nicht weiterverfolgen. Der britische Hochkommissar in Delhi hatte daraufhin über die Erfolgsaussichten keine Illusionen mehr: „Mr. Shastri did not absolutely reject the American draft; but in view of the discouraging Soviet reaction he gave Ambassador Bowles no reason to think that the Indians were attracted by the proposal. ... It looks as though the Indians will now try to brush this American proposal under the carpet and forget about it in the hope that everyone else will too. ${ }^{20} \mathrm{Im}$ State Department wollte man nun die Idee für eine Weile ruhen lassen und in Delhi sondieren, ob ein Interesse an einseitigen Garantien durch die USA bestehe. Die indische Regierung lehnte dies jedoch mit Hinweis auf die Blockfreiheit Indiens ab. Die Regierung in Delhi schien das Interesse an Sicherheitsgarantien ebenfalls verloren zu haben.

Die USA und Großbritannien setzten unterdessen die gemeinsamen Beratungen fort. Der amerikanische Botschafter in London gab dabei offen zu, daß die amerikanische Regierung momentan keine Antwort auf diese ungelöste Frage wisse. Er dachte dabei auch laut darüber nach, ob die USA möglicherweise nicht umhinkämen, den Indern auf dem

\footnotetext{
${ }^{17}$ NA, RG 59, CFPF, DEF 18, box 1591, Rusk to Bowles (US-Embassy, Delhi), 05. 05. 1965.

${ }^{18}$ Ebenda.

${ }^{19}$ PRO, FO 371/181401, FO to Brit. Embassy, Washington, 14. 05. 1965.

${ }^{20}$ PRO, FO 371/181401, Brit. High Commissioner, Delhi, to CRO, 27. 05. 1965.
} 
Weg zur Atommacht zu Hilfe zu kommen. ${ }^{21}$ Diese Überlegungen stellten jedoch keineswegs konkrete Pläne der amerikanischen Regierung dar, sondern waren Ausdruck einer gewissen Resignation angesichts der Unmöglichkeit, eine zufriedenstellende Lösung zu finden. Sollte Washington vor die Wahl zwischen einer bindenden Verpflichtung zur nuklearen Hilfe und einem unabhängigen indischen Atompotential gestellt werden, war das letztere sicher das geringere Übel.

Mit der Vorlage des britischen Entwurfs für einen Atomwaffensperrvertrag im Sommer 1965 war die britische Regierung gezwungen, in dieser Frage offiziell Stellung zu beziehen. Dieser britische Entwurf enthielt keine Sicherheitsgarantie. Diese Frage sollte separat gelöst werden. ${ }^{22}$ Der kanadische Vorschlag enthielt unterdessen mit Artikel IV eine eindeutige Verpflichtung aller Atommächte, den Nichtkernwaffenstaaten im Falle eines atomaren Angriffs umgehend zu Hilfe zu kommen. Aber selbst wenn die westlichen Atommächte zu diesem Zugeständnis bereit gewesen wären, hätte es zumindest im Falle Indiens keine Einigung gegeben. Der indische Delegierte in Genf, Trivedi, erklärte seinem kanadischen Kollegen Burns, der kanadische Vorschlag sei ungeeignet. Den Sicherheitsgarantien messe er wenig Bedeutung bei, da Indien Garantien in dieser Form nicht vertrauen könne. Statt dessen betonte Trivedi nun die Bedeutung von umfangreichen $\mathrm{Ab}$ rüstungsmaßnahmen, die ein Nichtverbreitungsvertrag enthalten müsse. ${ }^{23}$ Die Sowjetunion sah in ihrem Alternativvorschlag vom September 1965 ebenfalls keine Garantien vor. Zarapkin erklärte Foster in den bilateralen Gesprächen, er halte Garantien in Form einer Resolution der Vereinten Nationen - wie es die USA vorgeschlagen hatten - für verfrüht. Die Problematik solle nach Abschluß eines Abkommens gelöst werden. ${ }^{24}$

Die Nichtkernwaffenstaaten planten unterdessen, ihre Erwartungen hinsichtlich eines Nichtverbreitungsvertrages in Form einer Resolution zum Ausdruck zu bringen. Lord Chalfont rief im Hinblick auf diese Resolution die Nichtkernwaffenstaaten dazu auf, ihre Vorstellungen von Garantien zu konkretisieren und ihrerseits Lösungsvorschläge zu präsentieren. In den Diskussionen um diese Resolution war das Thema Sicherheitsgarantien allerdings nur ein Randaspekt und wurde von Indien überhaupt nicht zur Sprache gebracht. Im Mittelpunkt stand für Indien nun die Abrüstungsfrage. Auch die Resolution, die schließlich im November verabschiedet wurde, enthielt keine expliziten Forderungen nach Schutz vor nuklearer Bedrohung oder Erpressung. ${ }^{25}$

Obwohl die Sowjetunion Ende 1965 die Sicherheitsleistungen als derzeit noch nicht aktuelles Problem bezeichnet hatte, unterbreitete die Kreml-Führung Anfang Februar 1966 einen Vorschlag, um den Sicherheitsbedürfnissen der Nichtkernwaffenstaaten Rechnung zu tragen. Premier Kossygin schlug vor, den Einsatz von Kernwaffen gegen alle

21 "We may have to come to grips with the question of giving India a potential nuclear capability in some manner. . . this would present grave problems of various kinds, including the precedent for other countries in the area, the effect on Pakistan, etc., and said we have by no means thought the matter through to any conclusion as yet." LBJL, NSF, Country File: UK, box 208, Memo of Conversation, 12.06. 1965.

${ }^{22}$ Chalfont fürchtete endlose Diskussionen um Garantien, die den Abschluß des Vertrages verzögern würden. NA, RG 59, CFPF, DEF 18, box 1600, US-Embassy, London, to Dept of State, 27. 07. 1965.

${ }^{23}$ PRO, FO 371/181389, Memo of Conversation, 20. 07. 1965.

${ }^{24}$ PRO, FO 371/181402, Street (FO) to Watt (CRO), 09. 12. 1965.

${ }^{25}$ Documents on Disarmament 1965, S. 533-534. 
Staaten zu verbieten, auf deren Territorium sich keine Kernwaffen befänden. ${ }^{26}$ Der Kreml brachte die amerikanische Regierung damit in eine schwierige Lage. Dieser Plan fand bei den blockfreien Staaten erheblich mehr Anklang als ungenaue Zusagen in Form von feierlichen, aber unverbindlichen Resolutionen. Der sowjetische Vorschlag war jedoch unmittelbar gegen die Bundesrepublik Deutschland und im weiteren Sinn auch gegen alle NATO-Staaten gerichtet, auf deren Territorien amerikanische Kernwaffen lagerten. Deshalb begrüßte die amerikanische Regierung den Kossygin-Vorschlag zwar als Beitrag, das Problem der Sicherheitsleistungen zu lösen, gab aber zu erkennen, daß sie nicht bereit sei, diesen Plan mitzutragen. ${ }^{27}$

Lord Chalfont und Sir Harold Beeley bezeichneten den Vorschlag in seiner ursprünglichen Form als nicht annehmbar für die NATO, sprachen sich jedoch dafür aus, eine Kombination aus dem Kossygin-Vorschlag und einem Vorschlag Nigerias zu unterstützen. ${ }^{28}$ Nigeria hatte angeregt, einen atomaren Erstschlag gegen Länder zu verbieten, die nicht Mitglied einer militärischen Allianz unter dem Schutz einer Nuklearmacht waren. Das britische Außenministerium führte dagegen eine ganze Reihe von Gründen gegen den sowjetischen Vorschlag an und empfahl dringend, weiterhin den amerikanischen Kurs mit der Forderung nach positiven Garantien zu unterstützen. ${ }^{29}$ Chalfont und Wilson übergaben schließlich während ihres Besuchs in Moskau im März 1966 eine offizielle britische Antwort auf den Vorschlag. Darin wurde zwar die Initiative Moskaus begrüßt, aber darauf hingewiesen, daß das Problem Indien ungelöst bleibe. Die britische Regierung schlug vor, daß alle Unterzeichner eines NPT - Kernwaffenstaaten wie Nichtkernwaffenstaaten - sich in einer separaten Erklärung verpflichten sollten, einem Opfer nuklearer Aggression Hilfe zu leisten.

Die Ansprüche der Inder wurden unterdessen immer undurchsichtiger und unrealistischer. Im Februar hatte der indische Delegierte in Genf gefordert, ein freeze- und ein cut-off-Abkommen in den Nichtverbreitungsvertrag zu integrieren, um eine umfassende Abrüstung der Supermächte zu gewährleisten. Der indische Außenminister Singh erklärte in einem Gespräch mit Premierminister Wilson, eine Garantie der westlichen Atommächte sei unzureichend. Er sehe allerdings in absehbarer Zeit keine Chance für eine gemeinsame Garantieerklärung der USA und der Sowjetunion, die den indischen Erwartungen entspräche. Lord Chalfont reiste im Oktober nach Delhi, um endlich die genauen Vorstellungen der Inder zu klären und einen Kompromiß zu suchen. Chalfont berichtete Foster und dem amerikanischen Botschafter bei den Vereinten Nationen, Goldberg, über seinen Besuch, daß die indische Ministerpräsidentin Gandhi mit einer generellen multilateralen Garantie einverstanden zu sein scheine. Chalfont machte aber auch deutlich, daß

${ }^{26}$ Diese Form von Sicherheitsgarantien, die ein nukleares Angriffsverbot gegen bestimmte Staaten beinhaltet, wird als negative Garantie bezeichnet. Die amerikanischen Garantievorschläge, die Hilfe im Falle eines Angriffs vorsehen, wurden demgegenüber positive Garantien genannt. Zur Unterscheidung zwischen positiven und negativen Garantien und einer ausführlichen Diskussion der jeweiligen Vor- und Nachteile siehe: Shaker, Non-Proliferation, S. 472-490.

${ }^{27}$ NA, RG 59, CFPF, DEF 18, box 1593, Memo of Conversation, 27. 10. 1966.

${ }^{28}$ Beeley betonte vor allem die Bedeutung eines echten quid pro quo. Nichtkernwaffenstaaten, die den NPT nicht unterzeichneten, sollten nicht in den Genuß von Schutzleistungen kommen. PRO, FO 371/187461, Beeley to Street, 09. 02. 1966.

${ }^{29}$ Im Foreign Office wies man vor allem darauf hin, daß der sowjetische Plan der speziellen Situation Indiens nicht gerecht würde, da eine Beteiligung Chinas nicht zu erwarten sei. PRO, FO 371/ 187461, Memo by FO, 17. 02. 1966. 
auf diese Aussage keineswegs Verlaß sei. Er berichtete, er habe sich des Eindrucks nicht erwehren können, daß die Inder nun unerfüllbare Forderungen stellten, um damit eine Unterzeichnung des Vertrags ablehnen zu können. ${ }^{30}$ Foster gab in dieser Unterredung zu verstehen, daß die USA in der Frage der Sicherheitsgarantien noch keinen Schritt weitergekommen seien. Eine umfassende Garantie komme schon deshalb nicht in Frage, weil der Kongreß die Zustimmung verweigern würde. Angesichts der Situation in Vietnam war die Johnson-Regierung wenig geneigt, neue Verpflichtungen zu übernehmen. Zudem hatte man in Washington ein wachsendes Interesse daran, die Beziehungen zu Peking zu verbessern. Sowohl Chalfont als auch Foster gaben sich jedoch immer noch der Illusion hin, daß den Indern, wenn sich die Atommächte geeinigt hätten, gar nichts anderes übrigbleiben werde, als den Vertrag zu unterzeichnen. ${ }^{31}$ Dabei sprachen alle Anzeichen dafür, daß Chalfont mit seiner Vermutung, die Inder bereiteten ein Fernbleiben vom NV-Vertrag vor, ganz richtig lag.

Die indische Regierung hatte bereits im Dezember 1964 in London nachhaltiges Interesse an einem nationalen Atomprogramm zu erkennen gegeben. Das zivile indische Atomprogramm war weit entwickelt und bot eine ausgezeichnete Voraussetzung für den schnellen Bau einer Bombe. 1965 richtete Indien mit der Entwicklung eines Raketensystems die konventionelle Rüstung darauf aus, eine Basis für ein nukleares Trägersystem zu bilden. Eine Sicherheitsgarantie in Form einer UN-Resolution war den Indern zu wenig, weshalb sie in Moskau auch nicht weiter auf ein Zustandekommen dieser Lösung drängten. Moskau konnte Indien keine direkt gegen China gerichtete Schutzerklärung geben. Auch die USA waren zu weiterreichenden Verpflichtungen als einer UN-Resolution nicht bereit. Indien fühlte sich in dieser Frage von beiden Supermächten im Stich gelassen. Allerdings war die Regierung in Delhi zu keiner Zeit in der Lage, einen konkreten Vorschlag zu formulieren, der den indischen Erwartungen gerecht geworden wäre. Der Eindruck der chinesischen Bedrohung verstärkte sich durch den dritten chinesischen Atomtest Anfang 1966. Dadurch geriet die indische Regierung auch innenpolitisch immer mehr unter Druck. Nicht nur die Opposition, sondern auch weite Teile der Regierungspartei forderten nun öffentlich den Bau einer indischen Bombe. Die Regierung erklärte zwar, Indien stelle den nuklearen Verzicht nicht in Frage, bestätigte aber, daß die Vorbereitungen für eine schnelle Verwirklichung eines militärischen Programms auf Hochtouren liefen. Die Erklärungen von Ministerpräsidentin Gandhi und Außenminister Singh, die die deutsche Botschaft in Delhi nach Bonn übermittelte, waren vielsagend: „Allerdings unternehme Indien nach wie vor jede Anstrengung, um sein nukleares Potential in technischer und wissenschaftlicher Hinsicht so weit wie möglich zu entwickeln, damit es im Ernstfalle ohne allzu langen Zeitverlust auch für Verteidigungszwecke Verwendung finden könnte. ${ }^{\text {32 }}$ Indien beabsichtigte, sich die nukleare Option offenzuhalten. In Delhi ging es aber nicht nur um konkrete militärische Bedrohung, sondern auch um Prestige. Indien wollte in bezug auf Status und internationales Ansehen mit China auf einer Stufe stehen. In Indien war man unzufrieden darüber, daß China mit der Explosion der Bombe als Atommacht anerkannt wurde, Indien jedoch, das ein weit höher ent-

\footnotetext{
${ }^{30}$ NA, RG 59, CFPF, DEF 18, Goldberg to Dept of State, Record of Conversation, box 1593, 19. 10. 1966 .

${ }^{31}$ Ebenda.

${ }^{32}$ AdAA, Ref. II B 1, Bd. 977, Botschaftsrat Mirbach, Delhi, an AA, 11. 05. 1966.
} 
wickeltes Atomprogramm besaß, gleichsam degradiert wurde, weil es freiwillig auf den Bau der Bombe verzichtete. ${ }^{33}$

In den internationalen Verhandlungen verstanden es die Inder, sich als Kämpfer für die Interessen der Nichtkernwaffenstaaten, für nukleare Abrüstung und einen fairen Vertrag zu profilieren. Die deutsche Delegation in Genf, die nur Beobachterstatus hatte, gewann im Laufe der Gespräche von ihnen folgenden Eindruck: „Aus den bisher geführten Gesprächen ergab sich, daß die Inder im Rahmen ihrer eigenen Sicherheitserfordernisse flexibel taktieren und sich den diplomatischen weltpolitischen Erfordernissen mit großem Geschick anpassen. Sie waren bisher mit dieser Taktik so erfolgreich, daß Indien es bisher vermeiden konnte, als Saboteur der Non-Proliferation gebrandmarkt zu werden, obwohl die indische Regierung wegen der Atomdrohung an der Nordgrenze ihres Landes einstweilen gar nicht bereit ist, auf die nukleare Option zu verzichten. Dies wurde mir am Ende eines langen Gesprächs unmißverständlich versichert. ${ }^{\text {"34 }}$ Die Deutschen gelangten auch zu der Überzeugung, daß Indien im Grunde darauf hoffe, daß die Differenzen um die nukleare Beteiligung Deutschlands den Vertrag schließlich endgültig zu Fall bringen würden. Als sich in dieser Frage eine Einigung abzeichnete, wurde die Situation für Indien ungleich schwieriger. Die Anstrengungen Lord Chalfonts, eine Aufgabe der Hardware-Lösung durchzusetzen, einen Kompromiß über die Sicherheitsgarantien zu erzielen und dann möglichst schnell einen unproblematischen Vertrag zu unterzeichnen, waren Delhi ein besonderer Dorn im Auge.

Schließlich versuchte die indische Delegation in Genf sogar, die britische Delegation bei den Deutschen in Mißkredit zu bringen. Großbritannien habe über Pakistan eine Resolution eingebracht, mit dem Ziel, die Interessen der Nichtkernwaffenstaaten von dem eigentlichen NPT abzukoppeln und diese zu einer baldigen Unterzeichnung zu nötigen: „Aus indischer Abrüstungsdelegation verlautet, der pakistanische Vorschlag in den Vereinten Nationen eine Konferenz aller Nichtkernwaffenmächte einzuberufen, sei ein britischer Vorschlag, den die Briten lediglich von den Pakistanis lancieren ließen. Die Briten glaubten, mit einer auf einer solchen Konferenz zu formulierenden, für alle Seiten akzeptablen Fassung des Kossygin-Vorschlags, den Sowjets entgegenzukommen. Die britischen Vorstellungen gingen so weit, zu glauben, daß damit der NV-Vertrag für die Sowjets verlockender und annehmbarer werde. ... Die zur Zeit in New York zwischen den vier Genfer Westmächten stattfindenden Konsultationen zur Vorbereitung der Debatte im ersten Ausschuß seien wesentlich auf britischen Wunsch zurückzuführen. Es solle dabei auch wieder der Kossygin-Vorschlag erörtert werden. Aber auch sonst hätten die Briten vor ... die Amerikaner auf eine Einschränkung ihres NV-Vertrages zu drän-

${ }^{33}$ Der Prestigeaspekt wird in einer Rede des indischen Deligierten in Genf, Trivedi, besonders deutlich: „India has large uranium deposits and extensive thorium rich minerals, the largest in the world. We started work on our first reactor in 1955, ten years ago, and it became critical in 1956 - the first in Asia. Besides the four nuclear-weapon countries we are the only country having a plutonium extraction plant in operation. The country which wishes now to be described as a nuclear power in fact told us a few years ago that we were 15 years ahead of it in nuclear technology and yet, we have refrained from manufacturing nuclear weapons." AdAA, Ref. II B 1, Bd. 973, MD Diesel, New York, an AA, 27.10. 1965. Zur Frage nach der indischen Motivation für die Aufrechterhaltung der nuklearen Option siehe auch: Sahni, Going Nuclear, S. 85-108. Sahni mißt dem Prestigeaspekt ebenfalls erhebliche Bedeutung bei.

${ }^{34}$ AdAA, Ref. II B 1, Bd. 970, Keller (dt. Del. Genf) an AA, 02. 05. 1966. 
gen, derzufolge Hardware-Lösungen sowie eine europäische Kernstreitmacht im Vertrag ausgeschlossen werden sollten. ${ }^{35}$ Zur gleichen Zeit verlautete erstmals aus der indischen Delegation, daß Indien dem NPT nur beitreten werde, wenn auch Peking den Vertrag unterzeichne. ${ }^{36}$ Nachdem ein chinesischer Beitritt praktisch ausgeschlossen werden konnte, kam dies einer definitiven indischen Absage gleich.

\section{Sicherbeitsgarantien in Form einer Resolution der Vereinten Nationen}

Nachdem auch die Sowjetunion in den bilateralen Gesprächen deutlich gemacht hatte, daß sie ein Ende dieser Diskussionen wünsche, und die Frage der Garantien durch die Diskussion um die Überwachung des Vertrages verdrängt wurde, erlangte dieses Problem erst wieder Aktualität, als die Supermächte im August 1967 gleichlautende Vertragsentwürfe präsentierten. Ein Artikel über Sicherheitsgarantien war darin nicht enthalten. Der Vertreter Nigerias schlug daraufhin vor, folgende Formulierung als eigenen Artikel in den Vertrag aufzunehmen: "Each nuclear-weapon State Party to this treaty undertakes, if requested, to come to the aid of any non-nuclear weapon State which is threatened or attacked with nuclear weapons. ${ }^{“ 37}$ Nigeria fügte hinzu, daß sich der Schutz nur auf die Unterzeichner des NPT erstrecken solle. Der Vorschlag wurde nicht nur von den Kernwaffenstaaten negativ aufgenommen. Die Supermächte lehnten derart weitreichende Verpflichtungen ab, die Blockfreien fürchteten um die Wahrung ihres Status, und die Nichtkernwaffenstaaten, die mit einer Nichtunterzeichnung liebäugelten, waren selbstverständlich ebenfalls gegen diese Regelung.

Kanada schlug schließlich vor, parallel zum Vertrag sollten die Atommächte separate, aber gleichlautende Deklarationen abgeben, allen Nichtkernwaffenstaaten im Falle von nuklearer Erpressung oder Bedrohung zu Hilfe zu kommen. Als Alternative zu den Deklarationen könnten die Atommächte eine UN-Resolution einbringen, nach der sie Opfern eines nuklearen Angriffs Beistand leisten würden. Dieser Plan entsprach ziemlich genau den amerikanischen Vorstellungen und dürfte auf Bitten der amerikanischen Regierung von Kanada eingebracht worden sein. ${ }^{38}$ Ein kanadischer Vorschlag hatte als Initiative eines Nichtkernwaffenstaates erheblich mehr Chancen, von der internationalen Staatengemeinschaft akzeptiert zu werden, auch wenn er auf den Interessen der Atom-

${ }^{35}$ AdAA, Ref. II B 1, Bd. 965, Mangold (dt. Del. Genf) an AA, 10.10. 1966. Die Behauptung der Inder ist absolut unzutreffend. Die Briten waren über die pakistanische Initiative, eine Konferenz der Nichtkernwaffenstaaten einzuberufen, keineswegs erfreut. Großbritannien war erst bereit, der Resolution zuzustimmen, als ein Änderungsantrag Kuweits angenommen wurde, der vorsah, daß diese Konferenz nicht vor Mitte 1968 stattfinden sollte. FO 371/187471, FO to UK-Mission, New York, 10. 11. 1966. „Beeley added that UK continued hope that Pak Conference, [sic!] like WDC, would never eventuate." NA, RG 59, CFPF, DEF 18, box 1593, US-Ambassador to UN, Goldberg to Dept of State, 02. 12. 1966. Es muß an dieser Stelle allerdings auch noch einmal betont werden, daß weder der Kossygin-Vorschlag noch Garantien in Form einer Resolution der Vereinten Nationen geeignet waren, dem indischen Sicherheitsbedürfnis gegenüber der chinesischen Bedrohung gerecht zu werden.

${ }^{36}$ AdAA, Ref. II B 1, Bd. 965, Mangold (dt. Del. Genf) an AA, 10. 10. 1966.

${ }^{37}$ Zitiert nach: Shaker, Non-Proliferation, S. 523.

${ }^{38}$ Eine „Zusammenarbeit" in dieser Form war unter den Verbündeten durchaus üblich. Die USA hatten bereits früher über Irland eine Resolution eingebracht, um einer offenen Verurteilung der MLF zu entgehen. Siehe S. 142. 
mächte basierte. Washington hatte Anfang 1967 Delhi noch vergeblich bilaterale Diskussionen über Vorsorge- und Gegenmaßnahmen gegen mögliche nukleare Erpressungsversuche von seiten Chinas angeboten. ${ }^{39}$ Die Sowjetunion unternahm einen letzten Anlauf, sich mit Indien über einseitige sowjetische Garantien zu verständigen. Die sowjetischen Entwürfe gingen Delhi jedoch nicht weit genug. ${ }^{40}$ Daraufhin war auch die Kreml-Führung einverstanden, nicht auf ihrem Vorschlag zu beharren, sondern eine Lösung gemäß der kanadischen Initiative zu unterstützen. Der kanadische Vorschlag wurde schließlich in doppelter Hinsicht verwirklicht. Im März 1968 präsentierten die USA, Großbritannien und die Sowjetunion der Achtzehn-Mächte-Abrüstungskonferenz einen gemeinsamen Entwurf für eine Resolution des Sicherheitsrats der Vereinten Nationen. Zusätzlich beabsichtigten diese Atommächte, Deklarationen in der von Kanada vorgeschlagenen Version abzugeben.

Der Sicherheitsrat nahm nach heftigen Diskussionen in der Vollversammlung im Juni 1968 die folgende Resolution an: „1. [The UN Security Resolution 255] Recognizes that aggression with nuclear weapons or the threat of such aggression against a non-nuclearweapon State would create a situation in which the Security Council and above all its nuclear-weapon State permanent members, would have to act immediately in accordance with their obligations under the United Nations Charter; 2. Welcomes the intention expressed by certain States that they will provide or support immediate assistance in accordance with the Charter, to any non-nuclear-weapon State Party to the Treaty on the Non-Proliferation of Nuclear Weapons that is a victim of an act or an object of a threat of aggression in which nuclear weapons are used." ${ }^{\text {"1 }}$ Indien und Pakistan stimmten gegen diese Resolution, ebenso Frankreich. Die französische Regierung argumentierte, nur ein völliger Verzicht aller Nationen auf Kernwaffen könne die weltweite nukleare Bedrohung beenden. Indien kritisierte, daß die Resolution ausdrücklich nur für Unterzeichner des Atomwaffensperrvertrags gelte und sich nicht generell auf alle Nichtkernwaffenstaaten erstrecke. Gegen diese Lösung ließen sich auch noch weitere, stichhaltigere Kritikpunkte anbringen. Sollte eine der Garantiemächte zum Aggressor werden, wäre die Resolution hinfällig und der Sicherheitsrat handlungsunfähig. In diesem Fall würde das gesamte Sicherheitssystem sofort zusammenbrechen. Da nur drei der fünf Ständigen Mitglieder im Sicherheitsrat der Vereinten Nationen die Resolution unterstützten, bestand immer die Gefahr, daß der Sicherheitsrat im Falle eines Konfliktes durch ein Veto blokkiert werden würde. Die chinesische Republik (Taiwan), die China im Sicherheitsrat der Vereinten Nationen vertrat, hatte zwar für die Resolution gestimmt, aber dieses Votum war in bezug auf Indien bedeutungslos. Außerdem blieb die Frage offen, ob die Volksrepublik China in absehbarer Zeit wieder in die Vereinten Nationen aufgenommen werden würde. Die Resolution war zudem ganz offensichtlich gegen die Volksrepublik gerichtet, deren Außenseiterrolle in der internationalen Staatengemeinschaft damit bekräftigt wurde. Als Nichtmitglied der Vereinten Nationen hatte China auch keine theoretische Chance, sich irgendwann der gemeinsamen Garantieerklärung der Kernwaffenstaaten anzuschließen.

${ }^{39}$ LBJL, NSF, Subject File: NPT, box 26, Memo by Dept of State, 06. 04. 1967.

${ }^{40}$ LBJL, NSF, Subject File: NPT, box 26, Memo: Status of Negotiations on the Non-Proliferation Treaty, 08. 05. 1967.

${ }^{41}$ Zitiert nach: Shaker, Non-Proliferation, S. 471. 
Allerdings war diese Resolution das Ergebnis einer beachtlichen und bisher einzigartigen blockübergreifenden Zusammenarbeit. Eine Verständigung der beiden Supermächte war auf einem Gebiet möglich geworden, bei dem innerhalb der Blöcke die Bündnisdisziplin versagte und keine einheitliche Politik verfolgt wurde. Dies wurde auch von einer Mehrheit der Nichtkernwaffenstaaten positiv anerkannt. Es bestand aber der Wunsch, einen generellen Aufruf zum Gewaltverzicht in irgendeiner Form auch in den Nichtverbreitungsvertrag aufzunehmen. Dieser Gedanke wurde schließlich in der Präambel des Vertrages verankert. Während der Konferenz der Nichtkernwaffenstaaten sollte nach Möglichkeiten gesucht werden, die Garantien noch zu verstärken. Dort scheiterten jedoch zwei Anträge lateinamerikanischer und afrikanischer Staaten, von den Supermächten umfassende Nichtangriffsgarantien zu fordern. Die Konferenzteilnehmer konnten sich nur darauf verständigen, eine Resolution der Bundesrepublik Deutschland anzunehmen, die noch einmal die Prinzipien des Gewaltverzichts, der Nichteinmischung in die inneren Angelegenheiten anderer Staaten sowie des Rechts auf individuelle und kollektive Selbstverteidigung bekräftigte. Zudem wurde in der Schlußerklärung festgehalten, daß baldmöglichst die Schaffung eines umfassenden Sicherheitssystems angestrebt werden sollte, das den Erfordernissen des Atomzeitalters gerecht werde. ${ }^{42}$ Die Konferenz konnte sich in der Frage der Sicherheitsgarantien nicht zuletzt deswegen nicht auf weiterreichende Beschlüsse bzw. auf Forderungen an die Kernwaffenstaaten verständigen, da die Nichtkernwaffenstaaten, die durch das westliche oder östliche Bündnissystem ohnehin nuklearen Schutz genossen, dieser Frage weniger Bedeutung beimaßen als die blockfreien Staaten. Den meisten Staaten waren Fragen wie die Überwachung des Vertrags oder die Möglichkeiten zur friedlichen Nutzung der Kernenergie wesentlich wichtiger.

Großbritanniens Wünsche hinsichtlich der Form der Sicherheitsgarantien hatten sich damit weitgehend erfüllt. Es wurde eine Lösung gefunden, die nicht dazu führte, die Verhandlungen um den eigentlichen Vertrag endlos zu verzögern. Gleichwohl hatten es die USA und Großbritannien nicht geschafft, Indien in einen globalen Nichtverbreitungsvertrag einzubinden. In Washington und London hatte man zu lange gehofft, die Inder würden nach einer Einigung der Atommächte dem massiven internationalen Druck nicht widerstehen können und schließlich unterzeichnen. Sie hielten die zahlreichen Hinweise auf die Nichtbeteiligung für ein taktisches Spiel der Inder, um möglichst weitreichende Zugeständnisse der Supermächte zu erhalten. Indien hatte sich aber dafür entschieden, den militärischen Weg einzuschlagen. Dies geschah nicht nur aus militärisch-strategischen Erwägungen, sondern auch aus Prestigegründen. Großbritannien hatte sich bemüht, in Zusammenarbeit mit den USA eine Kompromißlösung für Indien zu finden. Lord Chalfont gab während seines Besuchs in Delhi den Indern sogar eine einseitige britische Garantie. ${ }^{43}$ Andererseits machten die Briten auch immer unmißverständlich deutlich, daß sie auf einen baldigen Abschluß des Vertrags drängten. Die Anliegen der Nichtkernwaffenstaaten - ob Sicherheitsgarantien oder Abrüstungsmaßnahmen - sollten erst nach ihrer Verzichtserklärung erörtert werden. Diese Haltung erweckte natürlich auch

${ }^{42}$ EA 23 (1968) 21, S. D 495-498 sowie S. D 544-546, Erklärung der Nichtkernwaffenstaaten, 28. 09. 1968.

${ }^{43}$ Dies berichtete die Times of India. Lord Chalfont äußerte sich dazu nicht explizit. Times of India, 11. 10. 1966. 
berechtigtes Mißtrauen. Die anglo-amerikanischen Bemühungen waren jedoch im Fall von Indien zum Scheitern verurteilt, da die indischen Forderungen die realistischen Möglichkeiten bei weitem überstiegen.

Weder die Sowjetunion noch die Vereinigten Staaten waren bereit, bindende Beistandsverpflichtungen einzugehen und allen Staaten, die keine Kernwaffen besaßen, im Gegenzug für ihren offiziellen Verzicht verbindliche Hilfe im Falle eines nuklearen Angriffs zuzusagen. Die Nichtkernwaffenstaaten bildeten in der Frage der Sicherheitsgarantien aber keine geschlossene Front, die auf umfassendem Schutz beharrte, da viele Staaten ohnehin unter dem Schutz einer nuklearen Supermacht standen. Die gemeinsame Resolution der USA und der Sowjetunion bedeutete aber ein außergewöhnlich weitreichendes Zusammenspiel der Supermächte. Diese Resolution dürfte einen gewissen Abschreckungseffekt auf Staaten wie Israel, die Vereinigte Arabische Republik oder Südafrika, die aus konkreten militärischen Erwägungen nukleare Ambitionen hatten, nicht verfehlt haben. Für diese Länder war es nun nicht mehr sonderlich attraktiv, im Konflikt mit dem verfeindeten Nachbarn einen Einsatz von Kernwaffen ins Auge zu fassen.

Indien blieb dem Vertrag schließlich unter anderem mit dem Hinweis auf unzureichende Sicherheitsleistungen für die blockfreien Nichtkernwaffenstaaten fern. Die indische Regierung unternahm in den Jahren 1967/68 auch keinerlei Initiativen mehr, Sicherheitsgarantien, die ihren Erwartungen gerecht würden, in den internationalen Gremien zu fordern, wie dies zum Beispiel die Vereinigte Arabische Republik oder Nigeria taten. Quester beschreibt das indische Verhalten in der Endphase der Verhandlungen folgendermaßen: „For a time in late 1967, it seemed that India might be trying to organize states such as West Germany, Japan, Sweden, and Italy into a nonsigning bloc. ... In spring 1968, perhaps at great-power behest, New Delhi apparently decided to avoid agitating against the treaty rather than simply to state its own unwillingness to sign. " ${ }^{\text {"44 }}$ Allerdings tat zu dieser Zeit die amerikanische und die sowjetische Außenpolitik gegenüber Indien ein übriges, das Vertrauen der Inder in die Supermächte zu ruinieren. ${ }^{45} \mathrm{Die}$ indische Nichtteilnahme zog automatisch das Fernbleiben Pakistans nach sich. Die folgende rasche Annäherung zwischen den USA und China machte schließlich auch die Aussichten auf einen Kurswechsel in Delhi zunichte. ${ }^{46}$

\footnotetext{
${ }^{44}$ Quester, Politics, S. 75. Vor allem 1966 gab es Konsultationen zwischen Indien und der Bundesrepublik sowie zwischen Japan und der Bundesrepublik. Die indischen Bemühungen, ein gang-up der Nichtnuklearen zu organisieren, dürften allerdings bereits 1967 abgeflaut sein.

${ }^{45}$ Quester schreibt hierzu: „To pressure India to sign the NPT, the United States presumably had some leverage in its policies on foreign aid, in direct programs and indirectly, as in World Bank decisions on non-project loan assistance. The Soviet Union had similar options in economic aid and military assistance programs and in its yearly U.N. Security Council votes on Kashmir. All such levers could have been used to pressure India to sign the Nuclear Non-Proliferation Treaty, but they were not. Nineteen sixty-eight saw the United States Congress reduce foreign aid and the Soviet Union offer military equipment to India's worst enemy, Pakistan.“ Quester, Politics, S. 57.

${ }^{46}$ Zur weiteren Entwicklung der Diskussion um die Sicherheitsgarantien nach dem NPT siehe: Bunn/Timerbaev, Security Assurances.
} 


\section{Die Überwachung des Nichtverbreitungsvertrages (Artikel III)}

\section{Wer wird kontrolliert? Die Diskussion über die Kontrollmodalitäten}

Mit der Präsentation der ersten Vertragsentwürfe im Sommer 1965 wurde die Frage aktuell, ob und in welcher Form Maßnahmen zur Überwachung der zivilen Atomprogramme (in den Verhandlungen kurz safeguards bezeichnet) in den NPT aufgenommen werden sollten. Die amerikanische Regierung drängte damals schon seit längerem darauf, die IAEO-Kontrollen grundsätzlich auf alle zivilen Nukleartransfers an Nichtkernwaffenstaaten zu erweitern. Um mit gutem Beispiel voranzugehen, stellten die USA 1964 einen zivilen Atomreaktor für Inspektionen zur Verfügung. Damit wollte man die Vorwürfe der Nichtkernwaffenstaaten entkräften, daß ausschließlich deren Atomprogramme diskriminierenden Kontrollen unterliegen sollten. Diese Politik sah vor allem der amerikanischen Kongreß zunächst als geeignete Maßnahme, um parallel zu den Bemühungen, ein Nichtverbreitungsabkommen zu erreichen, alle Möglichkeiten auszuschöpfen, die Weiterverbreitung von Kernwaffen zu unterbinden. In Washington war klar, daß ein NPT auch einen Artikel beinhalten sollte, der die umfassende Inspektion aller zivilen Nukleartransfers gewährleistete. Kongreß, Pentagon und ACDA waren dafür, die IAEO mit der Überwachung zu betrauen. Das State Department wollte mit Rücksicht auf die europäische Integration Euratom, die Atomenergiebehörde der europäischen Gemeinschaft, als gleichwertige Kontrollbehörde zulassen. In jedem Fall aber sollte ein Nichtverbreitungsvertrag adäquate Maßnahmen zur Überwachung beinhalten.

In London war man anderer Ansicht. Der erste britische Entwurf vom Juli 1965 enthielt keinen Artikel über safeguards, da die Briten fürchteten, dies würde zu Differenzen mit den Nichtkernwaffenstaaten führen. Die Briten argumentierten, sie wollten einen konsensfähigen Text präsentieren. Lord Chalfont machte einmal mehr deutlich, daß es den Briten um den zügigen Abschluß eines möglichst schlichten Abkommens ging. Die Kontrollfrage könne im Anschluß an den Vertrag verhandelt werden, so Chalfont. ${ }^{47}$ Der amerikanische Alternativvorschlag sah zunächst IAEO-Kontrollen oder gleichwertige Kontrollen (gemeint waren Euratom-Kontrollen) für alle Nichtkernwaffenstaaten vor. Die Kernwaffenstaaten sollten einen Teil ihres für zivile Zwecke bestimmten spaltbaren Materials kontrollieren lassen und den Nichtkernwaffenstaaten zur Verfügung stellen. Nachdem Großbritannien und Kanada einwandten, dies sei für einen Großteil der internationalen Staatengemeinschaft unannehmbar, fand ACDA-Direktor Foster für den Artikel III folgende Formulierung: „Each of the State Party to the Treaty undertakes to cooperate in facilitating the application of IAEA or equivalent safeguards. " 48 Kontrollen waren damit nicht mehr zwingend vorgeschrieben, aber nun sollten auch die Kernwaffenstaaten ihre zivilen Atomprogramme kontrollieren lassen.

Nun stand man in London vor dem Dilemma, daß die erste amerikanische Formulierung mit dem Hinweis auf die Diskriminierung der Nichtkernwaffenstaaten abgelehnt

${ }^{47}$ NA, CFPF, DEF 18, box 1600, Ambassador Bruce, London, to Dept of State, 23. 07. 1965.

${ }^{48}$ Bunn berichtet, daß Fosters Vorschlag zu heftigen Kontroversen in Washington führte: „Seaborg and Senator Pastore, Chairman of the Joint Committee on Atomic Energy, were outraged at Foster for not hanging tough to the first proposal, saying the fallback was weak and noncommittal." Bunn, Arms Control, S. 89. 
worden war, aber die amerikanische Alternative noch weniger akzeptabel war, da diese eine Kontrolle des britischen Atomprogramms zur Folge gehabt hätte. Die Regierung in London wollte den völligen Verzicht auf einen Kontrollartikel, da man von der Lieferung von spaltbarem Material aus den USA abhängig war und befürchtete, der Artikel III werde die amerikanischen Lieferungen an Großbritannien erheblich einschränken. ${ }^{49}$ Die amerikanische Delegation war schließlich sogar bereit, den Artikel III fallenzulassen. Nachdem aber mit den Briten keine Einigung über Artikel I und II erzielt werden konnte, legten die USA einen Entwurf vor, der Fosters Version des Kontrollartikels enthielt.

Der sowjetische Gegenvorschlag sah wie der britische Entwurf keinerlei Maßnahmen zur Überwachung des Abkommens vor. Die Briten standen damit nicht nur in der $n \boldsymbol{u}$ clear-sharing-Frage der Kreml-Führung näher als den engsten Verbündeten in Washington. Gleichwohl war auch diese Position nicht mehrheitsfähig, da die Nichtkernwaffenstaaten überwiegend strenge Kontrollmaßnahmen für alle Staaten forderten. ${ }^{50}$ In Washington zeigte sich unterdessen, daß der Kongreß auf einem strikten Kontrollartikel bestand und eine unverbindliche Formulierung, wie sie der amerikanische Entwurf von 1965 vorsah, nicht akzeptierte. ${ }^{51}$ Die ACDA, die Anfang 1966 an einem neuen Text arbeitete, mußte somit einerseits den Forderungen des Kongresses nach strikten Kontrollen Rechnung tragen, andererseits war sie bemüht, eine Lösung zu finden, die für die Briten akzeptabel war. Schließlich wollte man einen erneuten Disput um die Unterstützung des Vertragstextes vermeiden. In Washington wurde mit Rücksicht auf Großbritannien eine Formulierung gewählt, die verpflichtende Kontrollen für die Nichtkernwaffenstaaten vorsah und die Kernwaffenstaaten aufforderte, Kontrollen ihrer zivilen Atomprogramme zuzulassen. Diese Klausel war jedoch nicht verpflichtend. ${ }^{52}$ Die britische Regierung war nun bereit, diesen amerikanischen Vertragsentwurf zu unterstützen. $^{53}$

Damit war jedoch noch nicht geklärt, wie die Staaten, die keine Kernwaffen besaßen, zur Annahme dieser ungleichen Verpflichtungen gebracht werden sollten. Der amerikanische Entwurf stieß prompt bereits bei den westlichen Verbündeten, die in Genf vertreten waren, auf heftige Ablehnung. Die italienische Reaktion war negativ, und auch die Kanadier übten gegenüber ihren britischen Kollegen deutliche Kritik. Sie wandten ein, daß der Artikel einen Proteststurm der blockfreien Staaten auslösen werde. Zudem sahen die Kanadier die kommerziellen Interessen der westlichen Nichtkernwaffenstaaten beeinträchtigt. Die Kontrollen benachteiligten Kanada im Wettbewerb um Exportaufträge in der zivilen Technologie, da die nichtnuklearen Exportländer der Gefahr von Industriespionage schutzlos ausgeliefert seien. General Burns präsentierte den Briten umgehend

${ }^{49}$ NA, CFPF, DEF 18, box 1600, US-Del., Geneva, to Dept of State, 05. 08. 1965. Bunn schreibt, die Briten hätten Kontrollen für die Nichtnuklearen favorisiert. Bunn, Arms Control, S. 88. Dies ist nicht richtig.

${ }^{50}$ Der kanadische Vertragsentwurf hatte eine Kontrolle aller Unterzeichnerstaaten vorgesehen. PRO, FO 371/181389, Canadian Draft Treaty, Juli 1965, ohne genaues Datum. Die Resolution der Nichtkernwaffenstaaten hatte zum Ziel, Schlupflöcher für Proliferation zu schließen und einen ausgewogenen Vertrag anzustreben. Damit war auch eine strikte Überwachung aller zivilen Atomprogramme gemeint. ENDC/158 submitted to ENDC/PV. 233, 15. 09. 1965.

${ }^{51}$ Dies ging aus der Pastore-Resolution vom 18.01.1966 deutlich hervor. Bunn, Arms Control, S. 73.

52 PRO, FO 371/187464, Proposed Revision of Article III, 23. 03. 1966.

${ }^{53}$ PRO, FO 371/187464, Street (FO) to Richardson (UK-Del. Geneva), 30. 03. 1966. 
einen kanadischen Gegenvorschlag, den Lord Chalfont wiederum als nicht annehmbar bezeichnete. Chalfont erklärte nochmals, daß er eine Streichung des Kontrollartikels für den besten Weg halte. Er begründete diese Haltung mit der Problematik, daß die meisten britischen Atomanlagen sowohl für zivile als auch für militärische $Z$ wecke genutzt wurden. Chalfont argumentierte auch, daß die Sowjetunion ohnehin keiner Inspektion ihrer zivilen Kernanlagen zustimmen werde. General Burns erwiderte daraufhin, dann solle es auch der Sowjetunion überlassen bleiben, diese Haltung vor den Vereinten Nationen zu rechtfertigen. ${ }^{54}$ Die Differenzen zwischen den Briten und den Kanadiern bzw. den Italienern konnten somit nicht beigelegt werden. Innerhalb des westlichen Bündnisses war vorläufig keine Einigung über einen Artikel III möglich.

In London fürchtete man unterdessen, daß die britische Position in Washington auf wachsende Kritik stoßen werde. Der Kongreß machte die Briten bereits dafür verantwortlich, daß die Durchsetzung strikter Kontrollen blockiert war. Richard Faber von der britischen Botschaft in Washington äußerte sich besorgt über das Konfliktpotential, das die ungelöste Frage der Überwachung für Großbritannien barg: „The American redraft of Article III was of course devised to be helpful to us and I realise that, if the Canadians were not being so tiresome, we would be supporting it. What I am afraid of, however, is that if - because of the Canadian attitude - we lead a movement to revert to the original US formula [Artikel III des Entwurfs vom Sommer 1965, den Kanada akzeptiert hatte], we shall be picked out by the Joint Committee as having once more sabotaged American efforts to tighten up the safeguards provisions. ${ }^{\text {"55 }}$ In Washington fand sich unterdessen ein Konsens für die Position, verpflichtende Kontrollen ausschließlich für die Nichtkernwaffenstaaten zu fordern, auch wenn es schwierig werden würde, diese zu einer Annahme eines diskriminierenden Kontrollartikels zu bewegen. Damit wäre aber immerhin der massiven Kritik des Kongresses an einer Lösung, die auf unverbindliche Inspektionen aller Unterzeichnerstaaten hinauslief, Rechnung getragen worden. Die ACDA-Führung versuchte nun, London zu einem Einlenken zu bewegen.

Anfang Juli 1966 reiste ACDA-Vizedirektor Fisher nach London, um mit den Briten eine modifizierte Version des safeguards-Artikels zu diskutieren. Demnach sollte der Transfer von Atomanlagen, Ausrüstung und spaltbarem Material für zivile Zwecke nicht nur an Nichtkernwaffenstaaten, sondern an alle Staaten kontrolliert werden. Mit dieser Änderung kam man den kanadischen Forderungen ein Stück weit entgegen. Die Regierung in Ottawa hatte sich mit dieser Lösung einverstanden erklärt. Die britische Regierung sträubte sich jedoch vehement gegen die Änderung. Sie argumentierte in der Besprechung mit den amerikanischen Kollegen, daß Großbritannien als einziger Kernwaffenstaat auf den Import von spaltbarem Material angewiesen und damit im Vergleich zu den Supermächten benachteiligt sei. Großbritannien könne das Problem der mixed plants, d. h. der Atomanlagen, die sowohl für zivile als auch für militärische Zwecke arbeiteten, in absehbarer Zeit nicht lösen und fürchte Nachteile für das militärische Atomprogramm. Besonders ärgerlich war man in London darüber, daß auch die gerade vertraglich verlängerten bilateralen Transfers von spaltbarem Material zwischen den USA und Großbritannien unter die Kontrollen fallen sollten. Die britische Seite wandte darüber hinaus ein, daß die neue Fassung für die Mehrheit der Nichtkernwaffenstaaten im-

${ }^{54}$ PRO, FO 371/187464, Richardson to Street, 15. 04. 1966.

${ }^{55}$ PRO, FO 371/187464, Faber (Brit. Embassy, Washington) to Street (FO), 28. 04. 1966. 
mer noch nicht akzeptabel sei und deshalb niemanden geholfen sei. Außerdem erklärte sie, daß eine Vorlage eines Kontrollartikels zum gegebenen Zeitpunkt noch gar nicht erforderlich sei, vielmehr sollten die Vereinigten Staaten ihren Standpunkt in der safeguards-Frage vor der ENDC zum Ausdruck bringen und die Reaktionen der anderen Staaten abwarten. ${ }^{56}$ Die Besprechung endete schließlich ergebnislos.

Großbritannien weigerte sich, ein entscheidendes Zugeständnis zu machen oder wenigstens auf der Suche nach einem tragfähigen Kompromiß den Dialog mit Kanada zu suchen. Dies beeinträchtigte die Einigung im westlichen Lager und damit den gesamten Verhandlungsprozeß. Immerhin war die Position der unter den Nichtkernwaffenstaaten hochangesehenen Kanadier wegweisend für viele Staaten. Zur gleichen Zeit drängte die britische Regierung in Washington zur Aufgabe der majority voting option. Sie argumentierte, ein baldiger Vertragsabschluß sei wünschenswert, und die Vereinigten Staaten müßten im Interesse der Sache bereit sein, Kompromisse zu schließen. Dies galt offensichtlich nur für die USA, nicht aber für die Briten selbst. In der Frage des safeguards-Artikels war aus ihrer Sicht auch keine Eile vonnöten. Relevant war für London nur eine baldige Einigung der Supermächte über die grundsätzlichen Artikel. Die Besprechung über den Artikel III des NV-Vertrages zeigte auch, daß die Vereinigten Staaten zu dieser Zeit keinen ernsthaften Widerstand der blockfreien Staaten gegen diskriminierende Kontrollen in Betracht zogen. Indien und auch andere Blockfreie wie Brasilien hatten zwar mehrfach Inspektionen der zivilen und der militärischen Aktivitäten aller Staaten sowie die Überwachung eines gleichzeitigen Produktionsstopps für spaltbares Material als unerläßlich bezeichnet. Diese Forderungen wurden jedoch in Washington nicht ernstgenommen. ${ }^{57}$

Für Großbritannien schien sich das Problem von selbst zu lösen, als die sowjetische Delegation in den bilateralen Verhandlungen erklärte, die Sowjetunion könne unter keinen Umständen eine Kontrolle ihrer zivilen Atomindustrie akzeptieren. Im Foreign Office wollte man sich jedoch nicht darauf verlassen, daß damit die Frage der Inspektionen für Kernwaffenstaaten vom Tisch war. Man müsse davon ausgehen, daß die USA das Moskauer Nein nicht ohne weiteres hinnehmen würden. Für diesen Fall müsse man einen Alternativvorschlag parat haben, auch wenn der Verzicht auf einen Kontrollartikel nach wie vor für die beste Lösung gehalten würde. Falls die USA auf safeguards bestünden, könnten die Briten vorschlagen, alle nichtnuklearen Unterzeichnerstaaten sollten sich sofort einer Kontrolle sowohl ihrer Atomanlagen als auch aller nuklearen Importe unterziehen. Die Kernwaffenstaaten sollten nach Inkrafttreten des Abkommens fünf Jahre Zeit haben, um ihre zivilen und militärischen Anlagen zu entflechten. Danach würden auch die Kernwaffenstaaten verpflichtet sein, ihre gesamte zivile Atomindustrie kontrollieren zu lassen. Dieser Vorschlag sei für die Nichtkernwaffenstaaten akzeptabel, da er Ausgewogenheit und gleiche Pflichten garantiere und zugleich den Briten Zeit lasse, ihr militärisches Atomprogramm abzukoppein. Außerdem würde diese Initiative dem Westen einen billigen Propagandasieg bescheren, da es höchst unwahrscheinlich sei, daß die Sowjetunion diesen Vorschlag annehmen werde. ${ }^{58}$

${ }^{56}$ NA, RG 59, CFPF, DEF 18, box 1595, Memo of Conversation, 19. 07. 1966.

${ }^{57}$ Ebenda. Indien, so konstatierte ACDA-Vizedirektor Fisher in der Diskussion mit den Briten, werde noch eine Weile maßlose Forderungen stellen, aber schließlich einem fertigen Vertragstext zustimmen.

${ }^{58}$ Im Foreign Office veranschlagte man ungefähr diesen Zeitraum, um die Versorgung des militäri- 
In der Tat blieb die Sowjetunion in der Frage der Inspektionen unnachgiebig. Eine Kontrolle der zivilen Atomanlagen stand für die Kreml-Führung ebensowenig zur Diskussion wie die Inspektion der nuklearen Importe zu zivilen Zwecken. Gleichzeitig machte Moskau deutlich, daß die von den USA angestrebte Lösung, eine Kontrolle der EWG-Mitgliedstaaten ersatzweise durch Euratom zu ermöglichen, für die Sowjetunion nicht in Frage komme. Die Sowjetunion fürchtete eine Selbstinspektion der Bundesrepublik Deutschland und ein Schlupfloch für bundesdeutsche nukleare Ambitionen. Mit der starren sowjetischen Haltung waren im westlichen Lager die Diskussionen um die Frage, wer kontrolliert werden sollte, beendet. Nun galt es eine Antwort auf die Frage zu finden: Welche Institution kontrolliert die Nichtkernwaffenstaaten?

\section{Welche Behörde kontrolliert? IAEO versus Euratom}

Die Moskauer Position stieß in Washington durchaus auf ein gewisses Verständnis. Der AEC-Vorsitzende Seaborg forderte im Dezember 1966 zum wiederholten Male, ausschließlich die IAEO als Kontrollbehörde zuzulassen. ${ }^{59}$ Auch Spurgeon Keeny, einflußreiches Mitglied des Gilpatric Committee und Sicherheitsberater im Weißen Haus, erklärte in einem Memorandum zum safeguards-Artikel Euratom-Kontrollen für nicht wünschenswert: „I believe the Soviets have a very strong position since international inspection of the Euratom countries by Euratom is clearly self-inspection. Moreover, selfinspection by Euratom would be against our own self-interest since it would invite the establishment of similar procedures for Sovatom, Arabatom, etc. "60 Außenminister Rusk war jedoch der Ansicht, den europäischen Verbündeten sei es nicht zuzumuten, nun auch noch IAEO-Kontrollen zu schlucken. ${ }^{61}$ ACDA-Direktor Foster wollte daraufhin den europäischen Verbündeten einen Entwurf vorlegen, der IAEO-Kontrollen für alle Nichtkernwaffenstaaten vorsah, wobei den EG-Mitgliedstaaten eine gewisse Übergangsfrist eingeräumt werden sollte. ${ }^{62}$

Der Vorschlag wurde nicht nur von der Euratom-Kommission umgehend zurückgewiesen. Besonders harsche Kritik hagelte es aus der Bundesrepublik Deutschland. Im März 1967 hieß es in einer Denkschrift der Bundesregierung, der Vertrag dürfe die zukünftige Einigung Europas nicht stören und die friedliche Nutzung der Kernenergie nicht beeinträchtigen. ${ }^{63}$ Dies zielte ganz eindeutig auf die IAEO-Kontrollen, durch die die Bundesregierung neben Rückschlägen in der europäischen Integration vor allem Indu-

schen Komplexes mit spaltbarem Material sicherzustellen und die Atomanlagen in zivile und militärische Anlagen zu trennen. PRO, FO 371/187475, Memo by Mr. J. Street (FO), 06. 12. 1966.

${ }^{59}$ LBJL, NSF, National Security Council, box 55, History of the NPT, Seaborg to Rusk, 23. 12. 1966. Aus dem Schreiben geht auch hervor, daß Rusk mit seiner Präferenz für Euratom aus Rücksicht auf die Europäer wenig Unterstützung hatte. ACDA-Direktor Foster war ebenso für eine Aufgabe der Euratom-Lösung wie der amerikanische Botschafter bei den Vereinten Nationen, Goldberg. Auch innerhalb des State Departments hatten sich offensichtlich einige Stimmen für die IAEO als einzige Kontrollbehörde ausgesprochen. Siehe auch: Seaborg, Tide, S. 266-285.

${ }^{60}$ LBJL, NSF, Subject File: NPT, box 26, Memo by Spurgeon Keeny, 23. 06. 1967.

${ }^{61}$ Bunn, Arms Control, S. 93.

${ }^{62}$ Die genaue Formulierung lautete: „to accept IAEA safeguards on all peaceful nuclear activities as soon as practicable“, Bunn, Arms Control, S. 93. Am 1.Juli 1967 wurde aus EWG, Euratom und EGKG die EG.

${ }^{63}$ Zitiert nach: Haftendorn, Sicherheit, S. 663. Die bilateralen deutsch-amerikanischen Verhandlun- 
striespionage und kommerzielle Wettbewerbsnachteile fürchtete. ${ }^{64}$ Die ACDA konstruierte daraufhin ein System, nach dem sich Euratom und IAEO die Arbeit gleichsam teilen würden. Die Euratom sollte die Kontrollen der Europäer durchführen und die IAEO würde in bestimmten Abständen regelmäßig kontrollieren, ob die Euratom-Kontrollen dem Standard der IAEO entsprächen. Falls sich IAEO und Euratom innerhalb von drei Jahren auf keine Kontrollnormen für die EG-Mitgliedstaaten einigen könnten, würde automatisch die IAEO die Kontrollen übernehmen. Außenminister Brandt bezeichnete dies zwar als Schritt in die richtige Richtung, lehnte aber die Dreijahresfrist als "Guillotine“ für die Europäer ab. Ein weiterer amerikanischer Entwurf, der auf die Nennung einer zeitlichen Frist verzichtete, wurde schließlich Ende April von der Sowjetunion zurückgewiesen. Damit drohte die Kontrollfrage - nach der Einigung der Supermächte über die zentralen Artikel - den Nichtverbreitungsvertrag zum Scheitern zu bringen.

Die Differenzen um die Euratom als Kontrollbehörde brachten Großbritannien in eine schwierige Situation. Einerseits wollten die Briten den Vertrag so schnell wie möglich unter Dach und Fach bringen und hätten den sowjetischen Forderungen nach IAEOKontrollen gerne entsprochen, andererseits führte Großbritannien seit 1966 wieder Verhandlungen mit den Europäern über eine Aufnahme in die Europäische Gemeinschaft. In dieser Situation mußte die britische Regierung ihre Europazugehörigkeit unter Beweis stellen. In den Verhandlungen um den Nichtverbreitungsvertrag war daher viel Fingerspitzengefühl gefordert. Als Advokaten eines NPT betonten die Briten ihr Selbstverständnis als internationale Großmacht und die Bedeutung der anglo-amerikanischen special relationship. Die Europäer erwarteten jedoch ein Großbritannien, das seinen Platz innerhalb der europäischen Staatengemeinschaft sah und sich für die Interessen der Europäischen Gemeinschaft einsetzte. Die britische Regierung konnte es sich nicht leisten, die Zukunft der Euratom auf Spiel zu setzen und den NPT auch gegen die Interessen der nichtnuklearen Europäer voranzutreiben. ${ }^{65}$ Konkret bedeutete dies ein nachdrückliches britisches Engagement für Euratom. Bonn hatte die meisten Probleme mit dem NV-Vertrag, andererseits hatte die bundesdeutsche Regierung als Fürsprecher der Briten in Brüssel einiges Gewicht in die Waagschale zu werfen. Der von Lord Chalfont so häufig angemahnte harte Kurs gegenüber der Bundesrepublik konnte damit nicht weitergeführt werden. Nun mußte die britische Delegation in Genf die Interessen der Europäer, vor allem die der Bundesrepublik, vertreten.

Im Februar 1967 fragte das Foreign Office in Washington an, ob britische Vermittlungsdienste bei den europäischen Verbündeten erwünscht seien. Außenminister Rusk antwortete, britische Unterstützung in den problematischen Fragen wie der zivilen

gen und die deutsche Haltung zum Kontrollartikel sind genau dokumentiert bei: Küntzel, Bonn, S. 172-183. Haftendorn, Sicherheit, S. 632-692.

${ }^{64}$ Außenminister Brandt machte gegenüber den USA auch die besondere Rolle Frankreichs deutlich. Frankreich sei Mitglied in der Euratom, würde aber den NPT nicht unterzeichnen und damit als einziges Euratom-Mitglied nicht den IAEO-Kontrollen unterliegen. Damit entstünde für Frankreich ein kommerzieller Vorteil, da viele Firmen, um die IAEO-Kontrollen zu umgehen, nach Frankreich abwandern würden. LBJL, NSF, Subject File, box 26, Record of Conversation, 13. 12. 1967. Folglich war Frankreich auch nicht daran interessiert, in dieser Auseinandersetzung für die Euratom Partei zu ergreifen. Siehe hierzu auch: Küntzel, Bonn, S. 174.

${ }^{65}$ Die deutlichsten Warnungen kamen von der Financial Times. Siehe: Financial Times, 21. 01. 1967, 16. 02.1967 sowie 18. 02.1967. 
Atomtechnologie und besonders des Kontrollartikels sei willkommen, ebenso alle Maßnahmen, die den Europäern das Gefühl gäben, in Statusfragen den Briten nicht untergeordnet zu sein. Rusk betonte jedoch ausdrücklich, die Briten mögen es künftig unterlassen, eigene Vorschläge für eine Formulierung strittiger Artikel zu präsentieren. Mögliche britische Initiativen sollten auch nicht in Genf gestartet werden, damit amerikanische und britische Bemühungen sich nicht überschnitten oder sich gar in die Quere kämen. ${ }^{66}$ Kurz zuvor waren bereits Premierminister Wilson und Außenminister Brown nach Bonn gereist, um die Bundesregierung für eine Unterstützung des britischen Beitrittsgesuchs zu gewinnen und für den Nichtverbreitungsvertrag zu werben. ${ }^{67}$

Premierminister Wilson favorisierte außerdem bilaterale Expertengespräche zwischen britischen und deutschen Sachverständigen bzw. Vertretern der Euratom, um einen Meinungswandel hinsichtlich der geplanten IAEO-Inspektionen zu bewirken. ${ }^{68}$ Der technische Berater der britischen Regierung, Sir Solly Zuckerman, sollte zu diesem Zweck Anfang März zu Gesprächen nach Bonn kommen, Lord Chalfont verhandelte mit EuratomVertretern in Brüssel. Die Strategie der Labour-Regierung lief allerdings nicht darauf hinaus, sich in Genf für die Euratom als Kontrollbehörde stark zu machen. Die britische Regierung versuchte vielmehr in intensiven Konsultationen und Stellungnahmen, die Bedenken der Europäer gegen den NPT im allgemeinen und die IAEO im besonderen zu zerstreuen. Solly Zuckerman wies in Bonn darauf hin, daß die britische Regierung keine Vorbehalte dagegen habe, IAEO-Kontrollen in Großbritannien zuzulassen. Zuckerman sprach sich dafür aus, die IAEO nun zu akzeptieren und danach eine generelle Revision des IAEO-Kontrollsystems anzustreben, damit die Organisation den neuen Anforderungen gerecht werde. Nach dieser Revision solle es unter anderem allen Staaten möglich sein, bestimmte Inspektoren zurückzuweisen. ${ }^{69}$

Die britische Regierung wurde nicht müde, in einer Flut von Stellungnahmen sowohl die Argumente gegen IAEO-Kontrollen zu entkräften als auch die Europazugehörigkeit der Briten zu betonen. Ausgerechnet Lord Chalfont, der seit seinem Amtsantritt die special relationship als eines der wichtigsten Elemente der britischen Außenpolitik betrachtet hatte, erklärte nun, statt eines besonderen Verhältnisses zwischen Großbritannien und den USA sei jetzt ein besonderes Verhältnis zwischen den USA und den Vereinigten Staaten von Europa notwendig. Großbritannien fühle sich den Vereinigten Staaten von Europa zugehörig. ${ }^{70}$ Premierminister Wilson machte jedoch angesichts seines Pessimismus bezüglich de Gaullles Haltung zum britischen Beitritt bei einem Besuch in Washington im Juli 1967 seine Entschlossenheit deutlich, die anglo-amerikanischen Bande und die damit verbundene Großmachtrolle Großbritanniens nicht aufzugeben. ${ }^{71}$ Die Europa-

${ }^{66}$ LBJL, NSF, Country File: UK, box 210, Rusk to US-Embassy, London, 23. 02. 1967.

${ }^{67}$ PRO, PREM 13/1478, Record of Conversation, 16.02.1967.

${ }^{68}$ British Information Services, britische Nachrichten, 01. 03. 1967, Pressekonferenz Wilsons in Den Haag, 27. 02. 1967.

${ }^{69}$ PRO, PREM 13/1888, Record of Conversation, 03. 03. 1967.

70 British Information Services, britische Nachrichten, 12. 10. 1967, BBC-Interview mit Lord Chalfont, 09. 10. 67. Chalfont betonte auch später oft das Ende der anglo-amerikanischen special relationship und den Platz Großbritanniens in Europa, vor allem, nachdem er im Mai 1967 Delegationsleiter bei den Beitrittsverhandlungen in Brüssel wurde. The Guardian, 10. 10.1967.

${ }^{71}$ Darauf wird in einem Memorandum zur Vorbereitung auf den Besuch des britischen Außenministers Brown im Oktober 1967 ausdrücklich hingewiesen. LBJL, NSF, Country File: UK, box 216, Background Paper, Visit of UK Foreign Secretary Brown, UK-Policy Toward EEC, 10. 10. 1967. 
zugehörigkeit wurde also hauptsächlich über verbale Lippenbekenntnisse unter Beweis gestellt. Chalfont betonte auch, Großbritannien arbeite bereits seit 1959 mit Euratom zusammen und würde niemals ein Abkommen unterzeichnen, das die europäische Zusammenarbeit bei der Entwicklung der Atomenergie für friedliche Zwecke behindere. ${ }^{72}$ Die Möglichkeit, doch noch eine Lösung für die Anerkennung der Euratom zu finden, wurde jedoch nicht ins Auge gefaßt. ${ }^{73}$

In London setzte man außerdem auf die hochentwickelte zivile Atomindustrie Großbritanniens als Anreiz für die Europäer, das Vereinigte Königreich in die Gemeinschaft aufzunehmen. Der Abschluß des Nichtverbreitungsvertrages und der britische EG-Beitritt würden den Grundstein für eine intensive Zusammenarbeit auf dem Sektor der zivilen Atomenergie legen, erklärte die Labour-Regierung. Premierminister Wilson behauptete, der Vertrag sei alles andere als ein Hindernis für eine britische Mitgliedschaft im Gemeinsamen Markt. Vielmehr sei er einer solchen geradezu förderlich, denn Euratom könne wesentlich von dem Beitrag profitieren, den Großbritannien auf dem Gebiet der friedlichen Nutzung der Atomenergie anzubieten habe. In bestimmten Bereichen der zivilen Kernenergie sei Großbritannien heute in der Welt führend. ${ }^{74}$ Solly Zuckerman argumentierte, Europa könne nur gemeinsam die Vormachtstellung der USA auf dem Sektor der zivilen Atomtechnologie brechen. Aus diesem Grund solle Großbritannien baldmöglichst Mitglied der Euratom werden. ${ }^{75}$

Zivile nukleare Kooperation mochte Italien und der Bundesrepublik verlockend erscheinen, Frankreich war damit nicht zu beeindrucken. Die Weitergabe militärischer nuklearer Technologie als Lockvogel in den Verhandlungen mit de Gaulle wurde deshalb ebenfalls in Betracht gezogen. Der britische Botschafter in Frankreich schlug in einem Schreiben an Fred Mulley, Verhandlungsführer der Briten in Brüssel, vor, de Gaulle das technologische Know-how zum Bau der H-Bombe zur Verfügung zu stellen. ${ }^{76}$ Überlegungen dieser Art führten aber, so scheint es, zu keinem offiziellen Angebot. ${ }^{77}$ Die briti-

${ }^{72}$ British Information Services, britische Nachrichten, 15. 03. 1967, Rede Lord Chalfonts vor Vertretern der Euratom in Brüssel, 09. 03. 1967. Gleichzeitig erklärte Chalfont vor der ENDC: "My clear impression is that if there are to be safeguards they must be international and the treaty must not be the subject of self-policing." The Times, 24.02.1967.

${ }^{73}$ Die Briten betonten vielmehr die Argumente, die für IAEO-Kontrollen sprachen: „The British reply that unless IAEA inspection is accepted, the Russians will not sign the treaty so that the Germans would be throwing out the baby with the bath water." Financial Times, 16. 02.1967.

${ }^{74}$ British Information Services, britische Nachrichten, 01. 03. 1967, Pressekonferenz Wilsons in Den Haag, 26. 02. 1967. Lord Chalfont wurde in einer Rede vor dem Europarat noch konkreter und stellte den Europäern lukrative Technologietransfers in Aussicht. British Information Services, britische Nachrichten, 02.10.1967, Lord Chalfont vor dem Europarat in Straßburg, 26.09. 1967, The Times, 27.09. 1967.

${ }^{75}$ PRO, PREM 13/1888, Record of Conversation, 03. 03.1967.

${ }^{76}$ "Our information is that the French do not yet know how to make a thermo-nuclear bomb. If this is correct, the General faces the humiliating prospect of having a completely useless nuclear submarine force on his hands in a few years' time, unless the French have made the breakthrough by then. In this situation, the General might be tempted if we could offer to tell him how to make a thermo-nuclear bomb as soon as we are safely in the E.E.C. with his help." PRO, PREM 13/ 1479, Sir Patrick Reilly to Fred Mulley, 20. 04. 1967.

${ }^{77}$ Reilly schrieb, ein Angebot könne nur in einem "Tête-à-tête zwischen de Gaulle und Wilson" erfolgen. Aus den Gesprächsprotokollen ergeben sich jedoch keine Hinweise. Im Foreign Office hatte man zunächst versucht, die Weiterleitung dieses Schreibens an den Premierminister zu verhindern. PRO, PREM 13/1482, Memo for the Prime Minister, 13. 05. 1967. 
schen Angebote zur zivilen Zusammenarbeit wurden dagegen in Frankreich wahrscheinlich mit Mißfallen betrachtet und dürften eher gegen die britische Aufnahme gesprochen haben. Die kommerziellen Offerten der Briten liefen auf eine Kampfansage an die französischen Anbieter auf dem europäischen Atomenergiemarkt hinaus. Die britischen Versprechungen, die vor allem an Bonn und Rom gerichtet waren, bedeuteten in Paris unliebsame Konkurrenz.

Im April 1967 reiste Bundesaußenminister Brandt nach London. Auch bei diesem Besuch war der Nichtverbreitungsvertrag eines der Hauptthemen, die Brandt mit seinem britischen Kollegen besprach. ${ }^{78}$ Brandt ging es vor allem um mögliche kommerzielle Nachteile für die Bundesrepublik. Amerikanische Anbieter ziviler Atomenergie hätten auf dem Markt bessere Chancen, da die Käufer keinerlei Probleme mit Kontrollen befürchten müßten. Eine amerikanische Firma hätte bereits versucht, bundesdeutsche Konkurrenz mit diesem Argument auszuschalten. ${ }^{79}$ Brandt forderte daher, daß in jedem Fall auch die zivilen Bereiche der USA und Großbritanniens Kontrollen unterworfen sein sollten, auch wenn die Sowjetunion nicht zu diesem Schritt bereit sei ${ }^{80}$ Unmittelbar nach den Gesprächen mit Brandt traf eine Anfrage im Foreign Office ein, ob Großbritannien bereit sei, zusammen mit den USA einige zivile Atomanlagen freiwilligen Kontrollen zu unterstellen, um den deutschen Vorbehalten Rechnung zu tragen. ${ }^{81}$ Einen derartigen Schritt hatten die Briten bisher abgelehnt. Nun ging es darum, einen Zusammenbruch der Verhandlungen zu verhindern und bundesdeutsche Bedenken zu entkräften, ohne damit gleichzeitig sowjetische Ablehnung zu provozieren. Dieses Angebot sollte auch nicht als Verpflichtung in den eigentlichen Vertrag aufgenommen werden. In London wußte man, daß es keine andere Wahl gab, als der amerikanischen Initiative zu folgen, ohne die eigene Glaubwürdigkeit zu verlieren. Ende April 1967 unterbreiteten die USA und Großbritannien den NATO-Staaten unter Vorbehalt ein entsprechendes Angebot. ${ }^{82}$

Die USA und die Sowjetunion kamen unterdessen überein, im August der ENDC in Genf zunächst gemeinsame Vertragsentwürfe zu präsentieren, die den strittigen Kontrollartikel offenließen. Als Reaktion auf die Unfähigkeit der Supermächte, einen Artikel III auszuarbeiten, legte Schweden schließlich einen entsprechenden Entwurf vor, der IAEO-Kontrollen für alle zivilen Atomtransfers - sowohl der Kernwaffenstaaten als auch der Nichtkernwaffenstaaten - vorsah. ${ }^{83}$ Schweden hatte damit eine Mehrheit der Nichtkernwaffenstaaten, vor allem der Industrienationen, hinter sich, die eine Gleichbehandlung wünschten, da sie sonst kommerzielle Benachteiligung und Industriespionage befürchteten. Die Schweiz forderte kurze Zeit später ebenfalls Kontrollen für alle Vertragsparteien, um gleiche Wettbewerbsbedingungen zu garantieren. Dabei war auch diesen Nationen klar, daß eine Öffnung der sowjetischen Atomanlagen für Inspektionen un-

\footnotetext{
${ }^{78}$ Financial Times, 14. 04. 1967 und 16. 04. 1967, The Times, 15. 04. 1967.

${ }^{79}$ Tatsächlich waren die deutschen Klagen in diesem Punkt berechtigt. Der amerikanischen und der britischen Regierung war zu diesem Zeitpunkt bereits ein weiterer Fall bekannt. PRO, PREM 13/ 1888, Memo of Conversation between Prime Minister Wilson and Vice-President Humphrey, 04. 04. 1967.

${ }^{80}$ PRO, PREM 13/1888, Record of Conversation, 12.04. 1967. Dieses Problem war auch ein Hauptaspekt in den Gesprächen mit Zuckerman gewesen.

${ }^{81}$ PRO, PREM 13/1888, Brit. Embassy, Washington, to FO, 13. 04. 1967.

${ }^{82}$ PRO, PREM 13/1888, Brit. Del. to NATO to FO, 20. 04. 1967.

${ }^{83}$ Shaker, Non-Proliferation, S. 669.
} 
realistisch war. Aus diesem Grund sah der schwedische Vorschlag nur eine Überwachung der Transfers als verpflichtend vor. Eine Inspektion der zivilen Atomanlagen war zwar dringend erwünscht, aber für die Atommächte nicht verbindlich. In diesem Punkt ging es den nichtnuklearen Industrienationen auch viel mehr darum, gleiche Wettbewerbsbedingungen unter den Nationen zu schaffen, die nicht dem östlichen Bündnissystem angehörten, als eine Inspektion der zivilen sowjetischen Anlagen zu erreichen. Andere Nichtkernwaffenstaaten wie Indien oder Brasilien forderten eine Inspektion aller zivilen und militärischen Atomanlagen sowie aller Nuklearexporte ${ }^{84}$ Erklärtes Ziel dieser Staaten war es, auf einen umfassenden Produktionsstopp für Kernwaffen hinzuarbeiten. Diese Forderungen waren höchst unrealistisch und können nur als fundamentale Opposition gegen ein Abkommen im Rahmen der bestehenden Möglichkeiten gewertet werden.

Eine Gleichbehandlung von Kernwaffenstaaten und Nichtkernwaffenstaaten in der Kontrollfrage war mit der Sowjetunion nicht zu haben, aber die USA gaben schließlich im Dezember 1967 ihr Angebot, einige zivile Atomanlagen in den Vereinigten Staaten für Inspektionen zur Verfügung zu stellen, offiziell bekannt. Damit wurde der Beschluß von 1964, einen amerikanischen Reaktor für Kontrollen freizugeben, erheblich erweitert. Großbritannien folgte der amerikanischen Initiative wenig später. Die britische Regierung war aber immer noch nicht bereit, umfassende Kontrollen des zivilen Atomprogramms zuzulassen. Die britische Offerte enthielt eine Fülle von Ausnahmeregelungen, um eine absolute Geheimhaltung des mit dem zivilen Sektor verflochtenen militärischen Atomprogramms zu gewährleisten. Das entsprechende Abkommen mit der IAEO trat in Großbritannien erst 1978 in Kraft ${ }^{85}$ Während in Genf über den unvollständigen Vertragstext diskutiert wurde, gingen die bilateralen Verhandlungen zwischen den USA und der Sowjetunion über den strittigen Artikel III weiter. ${ }^{86}$

Die Verbündeten waren davon nicht informiert. Die beiden Delegationen konnten sich relativ bald auf eine Lösung einigen, die die IAEO als oberste Kontrollbehörde festschrieb. Die unterzeichnenden Nichtkernwaffenstaaten sollten mit der IAEO ein Abkommen schließen, damit das Kontrollsystem in dem jeweiligen Land zur Anwendung kommen konnte. Das Abkommen konnte jeder Staat individuell mit der IAEO schließen, oder aber mehrere Staaten im Verbund, was nichts anderes als eine Umschreibung für die Euratom bedeutete. ${ }^{87}$ Dieser Kompromiß existierte jedoch nur auf Delegationsebene und mußte zunächst den Regierungen in Washington und Moskau vorgelegt werden. Die Delegationsleiter griffen nun zu einem taktischen Manöver: Foster präsentierte den Kompromiß als Vorschlag Roschtschins, dieser legte ihn in Moskau als neuen Vorschlag der Vereinigten Staaten vor. Damit entsprachen beide Seiten ihren Vorgaben, nicht

${ }^{84}$ Ebenda, S. 668.

${ }^{85}$ Walker, Proliferation, S. 215.

${ }^{86}$ Diese letzte Runde der Verhandlungen wird sowohl von Seaborg als auch von Bunn detailgenau dargestellt und deshalb hier nicht ausführlich behandelt. Siehe: Bunn, Arms Control, S. 93-98 und Seaborg, Tide, S. 292-304.

${ }^{87}$ Bunn, der an der Ausarbeitung der Kompromißformel beteiligt war, schreibt hierzu: „The most important concession... [we] made was to hide references to Euratom in the ,individually or together" language. We agreed to language requiring acceptance of IAEA safeguards defined, of course, by the IAEA-Euratom negotiation. Our next, most important, concession was probably to shorten the time for IAEA-Euratom negotiations from three years to eighteen months. ... The Soviets' biggest concession, a substantial one, was to accept the Fisher idea that IAEA would verify Euratom safeguards, rather than duplicate them. .." Bunn, Arms Control, S. 97. 
von der eigenen Position abzuweichen. ${ }^{88}$ Die USA hatten der Bundesregierung versprochen, den amerikanischen Vorschlag nicht ohne vorherige Konsultationen abzuändern. Der neue Text wurde den Verbündeten im NATO-Rat als jüngster sowjetischer Kompromißvorschlag präsentiert. Die Benelux-Staaten reagierten positiv auf den Roschtschin-Entwurf, ebenso Großbritannien und Kanada, sowie Japan, das zunächst einer Sonderrolle der Euratom skeptisch gegenübergestanden hatte. Die Euratom-Kommission, Italien und die Bundesrepublik Deutschland waren jedoch immer noch nicht zu einer Zustimmung bereit.

Die Bundesrepublik Deutschland und Italien akzeptierten den Roschtschin-Entwurf erst, nachdem noch eine geringfügige Änderung vorgenommen worden war. Die Akzentverschiebung sollte den Euratom-Kontrollen ein wenig mehr Bedeutung beimessen. ${ }^{89}$ In Moskau wurde diese Änderung jedoch abgelehnt. Die britische Regierung versuchte daraufhin, mit einem weiteren Formulierungsvorschlag die Situation zu retten. Die USA reagierten trotz einer früheren Bitte von Außenminister Rusk, keine britischen Entwürfe mehr vorzulegen, positiv, da sie glaubten, diese Formulierung hätte gute Chancen, von der Kreml-Führung angenommen zu werden. Sie unterschied sich wiederum nur in $\mathrm{Nu}$ ancen von den beiden jüngsten Entwürfen. Mit der britischen Formulierung war man aber in Bonn nicht einverstanden. ${ }^{90}$ Die Bundesregierung übergab Foster statt dessen eine weitere lange Liste mit deutschen Forderungen. In Washington wurde diese Haltung mehr und mehr als Provokation empfunden. Seaborg berichtet, daß Foster und Henry Smyth, der amerikanische Vertreter bei der IAEO, sowie er selbst nun davon ausgegangen seien, die Bundesrepublik lege es auf ein Scheitern der Verhandlungen an. Seaborg schlug Rusk vor, Bonn gegenüber andere Töne anzuschlagen. ${ }^{91}$ Die Sowjetunion akzeptierte jedoch überraschenderweise Ende des Jahres 1967 die modifizierte Version des Kontrollartikels, die sie zunächst abgelehnt hatte. Damit war das Eis gebrochen, und die beiden Supermächte konnten am 18. Januar der Achtzehn-Mächte-Konferenz schließlich einen vollständigen Vertragstext vorlegen. Die sowjetische Zustimmung war möglich geworden, nachdem die USA in weiteren bilateralen Verhandlungen Konzessionen in der Frage der Vertragsdauer gemacht hatten. Die Sowjetunion wollte den Vertrag

${ }^{88}$ Diese Episode berichten: Seaborg, Tide, S. 294, sowie Bunn, Arms Control, S. 98.

${ }^{89}$ Seaborg, Tide, S. 299. Der Roschtschin-Entwurf lautete folgendermaßen: „Each non-nuclear weapon state party to the treaty undertakes to accept safeguards in accordance with the Statute of the IAEA and the Agency's safeguards system, as set forth in an agreement to be concluded with the IAEA, ..." Die NATO-Verbündeten forderten folgende Formulierung: „Each non-nuclear weapon state undertakes to accept safeguards, as set forth in an agreement to be negotiated and concluded with the IAEA in accordance with the Statute of the IAEA and the Agency's safeguards system, ..." Zitiert bei: Seaborg, Tide, S. 299.

${ }^{90}$ LBJL, NSF, Subject File: NPT, box 26, Memo for the President by Adrian Fisher: Alternatives for the First Sentence of Article III, 05.12. 1967. Die britische Formulierung lautete: „Each non-nuclear weapon state party to the treaty undertakes to accept safeguards, as set forth in an agreement to be concluded with the IAEA in accordance with the Statute of the IAEA." Walker behauptet: "The Article III compromise lay in a phrase suggested by the British that safeguards agreements would be set forth in a separate agreement with the IAEA, rather than acceptance of IAEA safeguards as such." Walker, Proliferation, S. 216. Diese Interpretation erscheint angesichts der Darstellungen von Bunn und Seaborg fragwürdig. Weder Seaborg noch Bunn erwähnen jedoch die britische Initiative. Da beide äußerst detailgenau berichten, kann der britische Vorschlag nicht von herausragender Bedeutung gewesen sein.

${ }^{91}$ Seaborg, Tide, S. 300. 
zeitlich nur dann auf zunächst 25 Jahre mit anschließender Überprüfungskonferenz begrenzen, falls dafür das Rücktrittsrecht entfallen würde. Dies wurde von den USA im Gegenzug für die sowjetische Zustimmung zum Artikel III akzeptiert. Damit waren auch die Fragen nach Vertragsdauer und Rücktrittsrecht schon sehr früh gelöst. ${ }^{92}$ Die britische Regierung hatte geplant, in dieser Frage zu taktieren und die Stimmung unter den Nichtkernwaffenstaaten zu sondieren. ${ }^{93}$ Dies war mit der amerikanisch-sowjetischen Einigung hinfällig.

Der Vertragsentwurf wurde nun in der ENDC diskutiert. Dabei galten jedoch die Artikel I, II und III von vornherein als unantastbar. Die Supermächte betrachteten die Verhandlungen über diese zentralen Punkte als abgeschlossen. Sowohl der sowjetische Delegationsleiter als auch sein amerikanischer Kollege weigerten sich mit dem Hinweis auf die besonders sorgfältige Ausarbeitung dieser Artikel, Änderungswünsche entgegenzunehmen. ${ }^{94}$ Der Artikel III wurde damit bis zur Unterzeichnung des Abkommens nicht mehr weiter verändert. Die Konferenz der Nichtkernwaffenstaaten beschäftigte sich noch einmal mit der Kontrollfrage. Es wurde aber lediglich eine Anweisung an die Kernwaffenstaaten verabschiedet, den Versprechen, ihre zivilen Atomanlagen unter IAEO-Inspektion zu stellen, bald nachzukommen. ${ }^{95}$ Mit der Unterzeichnung des Nichtverbreitungsvertrages verpflichteten sich die Nichtkernwaffenstaaten, spätestens 180 Tage nach Inkrafttreten des Vertrages, Verhandlungen mit der IAEO über ein safeguards-Abkommen zu beginnen. Staaten, die später unterzeichneten, sollten zugleich mit der Ratifikation des Vertrages die Verhandlungen mit der IAEO aufnehmen. Die Kontrollen hatten den ausschließlichen Zweck, eine Verwendung von Atomenergie für militärische Zwecke zu verhindern. Sie durften ausdrücklich keine Behinderung der friedlichen Nutzung von Atomenergie mit sich bringen und technologische Fortschritte auf dem zivilen Sektor nicht blockieren. Die Unausgewogenheit der Verpflichtungen von Nuklearmächten und Nichtkernwaffenstaaten wurde durch diese genauen Vorgaben gemindert - ebenso wie durch die Erklärungen der USA und Großbritanniens, ihre Anlagen freiwillig für Inspektionen zur Verfügung zu stellen. Diese waren jedoch weder verpflichtend noch zeitlich gebunden und jederzeit widerrufbar. Nur die Nichtkernwaffenstaaten waren verpflichtet, in absehbarer Zeit und auf Dauer ihr gesamtes ziviles Atomprogramm überwachen zu lassen.

\section{Zivile Nutzung der Atomenergie und friedliche Atomexplosionen}

Die Atommächte hatten es zunächst nicht für erforderlich gehalten, den Nichtkernwaffenstaaten im Nichtverbreitungsvertrag den uneingeschränkten Zugang zu allen Bereichen der friedlichen Atomenergie explizit zu garantieren. Als jedoch die USA im Som-

${ }^{92}$ Italien hatte von den USA im Laufe des Jahres 1967 mehrfach nachdrücklich gefordert, die Vertragsdauer zeitlich zu begrenzen. Die italienische Regierung hatte jedoch nur vage Antworten von Außenminister Rusk erhalten. Zudem wollte die italienische Regierung ein Rücktrittsrecht im Vertrag verankert wissen. Nuti, ,Me too, please', S. 134-135.

${ }^{93}$ PRO, FO 371/181392, FO-Memo for the 20 th UN-General Assemby Session: Non-Proliferation, Sept. 1965, ohne genaues Datum.

${ }^{94}$ Shaker, Non-Proliferation, S. 116.

${ }^{95}$ EA 23 (1968) 21, S. D 499, 28. 09. 1968. 
mer 1966 vor der ENDC erklärten, ein NPT müsse auch ein Verbot friedlicher Atomexplosionen beinhalten, wuchs unter den Nichtkernwaffenstaaten die Sorge, die Kernwaffenstaaten würden den NPT dazu benützen, sich auch auf dem zivilen Sektor lukrative Monopole sowie einen Technologievorsprung zu sichern. In Großbritannien war diese Thematik bis dahin nur einmal kurz zur Sprache gekommen, als ein Mitglied der britischen Delegation in Genf, Mr. Duncan, anregte, den Nichtkernwaffenstaaten bestimmte zivile Technologien vorzuenthalten, um zivile Transfers als Möglichkeit zur Vorbereitung eines militärischen Programms auszuschließen. ${ }^{96}$ Sowohl im Foreign Office als auch im Verteidigungsministerium wurde dieser Vorschlag umgehend zurückgewiesen. ${ }^{97}$ Als die Nichtkernwaffenstaaten, allen voran die Bundesrepublik Deutschland, immer lauter Garantien gegen Beschränkungen auf dem zivilen Sektor forderten, reagierten die USA zunächst mit einer Rede des amerikanischen Präsidenten vor der ENDC, in der Johnson erklärte, die friedliche Entwicklung der Atomenergie solle durch den NPT in keiner Weise beeinträchtigt werden. ${ }^{98}$

Die USA versuchten, diese Bedenken der Bundesregierung auch in bilateralen Gesprächen zu widerlegen. Das State Department erklärte gegenüber der deutschen Regierung, daß eine umfassende Kooperation zwischen der Bundesrepublik und den USA auf dem zivilen Gebiet durch den NPT nicht behindert werden werde. ${ }^{99}$ Bundesaußenminister Brandt brachte das Argument vor, die zivile Technologie in den Kernwaffenstaaten profitiere von den Ergebnissen in der militärischen Forschung. Der deutschen Atomindustrie entstünden dadurch erhebliche Nachteile. Außenminster Rusk versicherte Brandt bei dessen Besuch im Februar 1967, keine Behinderung der zivilen Nutzung der Atomenergie eintreten zu lassen. ${ }^{100}$ Wie bereits beschrieben, tat die britische Regierung in den deutsch-britischen Konsultationen ebenfalls alles - nicht nur in bezug auf den Kontrollartikel, sondern auch was die friedliche Nutzung der Atomenergie betraf -, um die deutschen Bedenken zu zerstreuen. Lord Chalfont betonte mehrmals vor der ENDC, daß die britische Regierung die Rechte der Nichtkernwaffenstaaten auf uneingeschränkte Entwicklung der zivilen Technologie nicht beschneiden wolle. ${ }^{101}$ Die Briten hatten schon aufgrund ihrer Interessen auf dem nuklearen Exportmarkt keine Absichten, den Handel mit ziviler Technologie zu unterbinden. Gleichzeitig mußte man natürlich in dieser Frage auf die Europäer besondere Rücksicht nehmen.

Die mexikanische Delegation in Genf schlug der ENDC schließlich eine Formulierung für einen Artikel zur Sicherung des Rechts auf Entwicklung der friedlichen Atomtechnologie vor. ${ }^{102}$ Der mexikanische Entwurf bildete die Vorlage für den Artikel IV des ersten gemeinsamen Vertragstextes der Supermächte. Die USA machten jedoch deutlich, daß

${ }^{96}$ PRO, FO 371/187465, Duncan to Stuart, 18. 05. 1966.

${ }^{97}$ PRO, FO 371/187465, Street to UK-Del., Geneva, 27.06. 1966 und PRO, FO 371/187465, Dr. Press (MOD) to Street, (FO), 10.06.1966.

${ }^{98}$ Seaborg, Tide, S. 360.

${ }^{99}$ Siehe hierzu: Haftendorn, Sicherheit, S. 681-682.

${ }^{100}$ Küntzel, Bonn, S. 163.

${ }^{101}$ Rede Chalfonts vor der ENDC am 23. 02. 1967, zitiert nach: The Guardian, 24. 02. 1967. Vgl. Lord Chalfont vor der ENDC am 21. 03. 1967: „No non-proliferation treaty is meant to impede civil nuclear development, and no treaty must be allowed to do so." ENDC/PV. 295, 21. 03. 1967.

${ }^{102}$ ENDC/PV. 295, 21. 03. 1967. 
der Artikel IV den Bestimmungen des Atomic-Energy-Acts und den amerikanischen Exportbestimmungen unterliege. Daraufhin verlangte eine Mehrheit der Nichtkernwaffenstaaten unter Führung Mexikos, es solle die Pflicht der Atommächte sein, den Staaten, die auf Kernwaffenbesitz verzichteten, bei der Entwicklung ihrer zivilen Atomprogramme konkrete Hilfe zu leisten. Kanada und Großbitannien wandten sich gemeinsam gegen diesen Vorstoß. Nach Ansicht der Kanadier waren die Nichtkernwaffenstaaten in diesem Punkt zu weit gegangen, da nach dieser Auslegung maßlose Forderungen geltend gemacht werden konnten. Der Regierung in London ging es um den finanziellen Aspekt. Die Nichtkernwaffenstaaten könnten nicht die Früchte der jahrelangen, kostenintensiven Forschungsarbeit der Atommächte kostenlos ernten wollen, erklärte Staatsminister Mulley, der Lord Chalfont als Verhandlungsführer der britischen Delegation in Genf abgelöst hatte. ${ }^{103}$ Damit sprachen sich die Briten nicht gegen umfangreiche Technologietransfers aus, nur umsonst wollte Großbritannien seine Erkenntnisse auf dem Gebiet der Atomforschung nicht weitergeben. Italien unternahm zwei Anläufe, über den Artikel IV die Versorgung der Nichtkernwaffenstaaten mit spaltbarem Material zu gewährleisten. ${ }^{104}$ Der freie Zugang zu den Ausgangsmaterialien sei die Voraussetzung für jedes zivile Atomprogramm, argumentierte die italienische Regierung und avancierte damit neben der Bundesregierung zum hartnäckigsten Opponenten jeglicher Beschränkung auf dem zivilen Sektor.

Die italienische Initiative wurde ebenso fallengelassen wie verschiedene andere Änderungswünsche nichtnuklearer Delegationen. Die Forderung nach einer Verpflichtung der Kernwaffenstaaten, zivile Technologie bereitzustellen, bezeichnete der amerikanische Vertreter in Genf, Fisher, als übertrieben. Er äußerte aber zugleich auch Verständnis für die Haltung der Nichtkernwaffenstaaten. ${ }^{105}$ Die endgültige Formulierung stellte schließlich eine Kompromißlösung dar. Die Atommächte unterlagen keiner expliziten Verpflichtung, aber alle Unterzeichnerstaaten, die dazu in der Lage waren, sollten zum Aufbau ziviler Atomprogramme in Nichtkernwaffenstaaten beitragen. Der Artikel IV verkörperte damit auch die Fortsetzung von Atoms-for-Peace in einer neuen, verbesserten Form. Die Formulierung, „Parties to the Treaty in a position to do so", war damit auch eine Aufforderung an die Nichtkernwaffenstaaten mit einem hochentwickelten Atomprogramm, sich auf diesem Gebiet zu engagieren und die Kooperation in der zivilen Kernkraft auch unter den Nichtkernwaffenstaaten zu fördern. Den britischen Vorstellungen von einer Förderung des Handels auf dem zivilen Sektor als Mittel zur Begrenzung von Proliferation wurde damit entsprochen. Der Artikel IV erhöhte einerseits die Attraktivität des Vertrages für alle Staaten und eröffnete andererseits der britischen Wirtschaft einen lukrativen Markt. Im Rahmen eines britischen Beitritts zur EG konnte der Artikel IV des Nichtverbreitungsvertrages die Basis für intensive Kooperation mit den Un-

${ }^{103}$ ENDC/PV. 337, 10. 10. 1967.

${ }^{104}$ Der erste Vorschlag forderte die Atommächte dazu auf, den Nichtkernwaffenstaaten eine bestimmte Menge an spaltbarem Material zur Verfügung zu stellen. Nachdem diese Initiative gescheitert war, wollte Italien wenigstens das Recht auf freien Zugang zu spaltbarem Material im Vertrag verankert wissen. ENDC/PV. 318, 01. 08. 1967 und ENDC/PV. 367, 20. 02. 1968.

${ }^{105}$ Die Frage der Sicherung des Zugangs zu friedlicher Technologie war hauptsächlich ein Konflikt zwischen den USA und den westlichen bzw. den blockfreien Staaten, da die meisten Nichtkernwaffenstaaten an westlicher Atomtechnologie interessiert waren. Die Sowjetunion hielt sich in dieser Frage sehr bedeckt. 
terzeichnerstaaten innerhalb der Gemeinschaft bilden. Zudem bestand die Aussicht, daß sich auch die globalen Exportmöglichkeiten erheblich verbesserten. Andererseits bedeutete er auch wachsende Konkurrenz. Der Artikel IV war gleichsam eine Einladung an die Bundesrepublik Deutschland, ihre hochentwickelte zivile Atomtechnologie in großem Maße zu exportieren.

Die Durchführung von Atomexplosionen zu friedlichen Zwecken (Peaceful Nuclear Explosion, kurz: PNE), zum Beispiel für wissenschaftliche Experimente oder verschiedene Großprojekte wie den Bau von Schiffahrtsstraßen oder Stauseen oder die Freilegung von Rohstoffvorkommen, war ein Problemfeld, das im Rahmen der friedlichen Nutzung der Atomenergie gesondert diskutiert wurde. Einerseits konnte gleichsam jeder Atomtest als friedlich deklariert und damit die Entwicklung von Waffen legalisiert werden. Andererseits war es besonders schwierig, den Nichtkernwaffenstaaten die Durchführung von friedlichen Explosionen zu verbieten, da gerade viele unterentwickelte Nationen der Dritten Welt hofften, mit Hilfe von atomaren Explosionen Probleme wie mangelnde Wasserversorgung oder den Abbau von bisher unerreichbaren Rohstoffen langfristig bewältigen zu können. ${ }^{106}$ Die nichtnuklearen Industrienationen wiederum konnten die Atommächte der Sicherung eines Technologiemonopols und der Zementierung unfairer Wettbewerbsbedingungen bezichtigen. Die Frage, ob PNEs in einem Nichtverbreitungsabkommen explizit verboten werden sollten, wurde aber erst mit dem amerikanischen Vertragsentwurf vom Frühjahr 1966 aktuell. Die Vertragsentwürfe vom Sommer 1965 hatten diese Problematik außer acht gelassen. Der überarbeitete amerikanische Entwurf enthielt jedoch im zentralen Artikel I des Vertragstextes eine Passage, die friedliche Atomexplosionen der Nichtkernwaffenstaaten verbot. ${ }^{107}$

Bei der Diskussion der Western Four in Genf über den neuen amerikanischen Entwurf brachten die Kanadier die Vor- und Nachteile eines Verbots friedlicher Explosionen zur Sprache. Sie wiesen darauf hin, daß die amerikanische Formulierung von den Nichtkernwaffenstaaten als diskriminierend zurückgewiesen und möglicherweise unerwünschte Gegenreaktionen auslösen werde: „The US proposal could be interpreted as leading to a monopoly by the nuclear powers - a limited comprehensive test ban, limited to the non-nuclear powers. The Indians might respond by racing ahead to conduct a peaceful test before a treaty could be agreed; or else they and the other non-aligned might renew their demands for a full comprehensive test ban or a moratorium. " $108 \mathrm{Ge}$ neral Burns warf aber auch die Frage auf, wie die Sowjetunion auf eine bundesdeutsche friedliche Explosion reagieren würde, und ob es möglich sei, PNEs unter internationaler Überwachung durchzuführen. Der ACDA-Vertreter Fisher betonte, daß friedliche Explosionen und Waffentests kaum zu unterscheiden seien. Die meisten friedlichen Explosionen seien bereits durch den PTBT verboten, und die Unterzeichnerstaaten hätten damals schon umfassende Restriktionen akzeptiert. Außerdem, so Fisher, hätten die USA Hinweise, daß in Indien eine sogenannte friedliche Explosion vorbereitet werde. Die

${ }^{106}$ Siehe hierzu: Shaker, Non-Proliferation, S. 416.

${ }^{107}$ Der amerikanische Vertragsentwurf von 1965 hatte diese Frage ausgeklammert, da innerhalb der amerikanischen Regierung unterschiedliche Auffasssungen bestanden, ob ein Verbot der friedlichen Explosionen wünschenswert sei. Die ACDA wollte ein Verbot, die AEC war dagegen, da dies möglicherweise ein generelles Verbot friedlicher Explosionen nach sich ziehen würde. Seaborg, Tide, S. 364.

${ }^{108}$ PRO, FO 371/187462, Richardson (UK-Del., Geneva) to Stuart (FO), 02. 03. 1966. 
Wirkung eines angeblich friedlichen Tests auf die internationale Staatengemeinschaft und die möglichen Reaktionen würden ähnlich sein wie bei einem militärischen Test. Fisher bezeichnete schließlich sogar einen NPT ohne Verbot der friedlichen Tests als nutzlos. ${ }^{109}$

Lord Chalfont sprach sich dafür aus, daß alle Nationen gleichermaßen von den Errungenschaften auf dem Gebiet der zivilen Atomenergie und damit auch von friedlichen Explosionen profitieren sollten. Er hielt das amerikanische Verbot für höchst diskriminierend und betrachtete auch eine indische Explosion keineswegs als ersten Schritt Indiens auf dem Weg zur militärischen Atommacht. Zudem, erklärte Chalfont, sei es taktisch höchst ungeschickt, die Nichtkernwaffenstaaten nun mit dieser Forderung zu konfrontieren. Dies werde den Abschluß eines Abkommens nur verzögern. Vielmehr könne darüber nachgedacht werden, Restriktionen dieser Art in einen CTBT aufzunehmen. ${ }^{110}$ Chalfonts Position war klar: Er wollte einem baldigen Vertragsabschluß keinerlei Hindernisse in den Weg legen. Klauseln, die Konfliktpunkte mit den Nichtkernwaffenstaaten bargen, sollten im Interesse einer breiten Akzeptanz des Abkommens weggelassen werden. In diesem Punkt war man jedoch in London anderer Ansicht als Lord Chalfont. Nach Rücksprache mit dem Verteidigungsministerium schrieb der Leiter des Atomic Energy Department im Foreign Office, Street, an die britische Delegation in Genf, daß die Regierung die amerikanische Einschätzung teile, der Vertrag solle Nichtkernwaffenstaaten die Durchführung von PNEs verbieten. Das Foreign Office gehe davon aus, daß eine friedliche Explosion eines Nichtkernwaffenstaates dem Beweis gleichkomme, daß dieser Staat in der Lage sei, Waffen zu produzieren. So würde dieser Test auch von allen anderen Staaten verstanden werden. ${ }^{111}$

Die USA waren entschlossen, das Thema nun zur Sprache zu bringen. Ende Juni übergab die amerikanische Delegation ihren sowjetischen Kollegen in Genf ein Memorandum, in dem der Vorschlag erörtert wurde, die Kernwaffenstaaten sollten friedliche Explosionen im Auftrag der Nichtkernwaffenstaaten durchführen. Nachdem Moskau nicht ablehnend reagierte, legten die USA den Plan im August der Achtzehn-Mächte-Konferenz vor. ${ }^{112}$ In der folgenden Zeit konzentrierte sich jedoch alles auf die Lösung der $n w$ clear-sharing-Frage und die grundsätzliche Einigung der Supermächte, so daß eine breitere Diskussion des amerikanischen Vorschlages bzw. anderer Lösungsmöglichkeiten nicht erfolgte. Die Briten sahen unterdessen in der Frage der friedlichen Explosionen eine ernsthafte Gefahr für einen baldigen Vertragsabschluß erwachsen. Die Reaktionen auf britischer Seite waren unterschiedlich. Die britische Delegation in Genf sprach sich gegenüber den amerikanischen Kollegen wiederholt dafür aus, das Problem auszuklammern und separat zu behandeln. ${ }^{113}$ Die britische Vertretung bei den Vereinten Nationen wies darauf hin, daß dieser Punkt wenigstens aus den zentralen Vertragsartikeln I und II gestrichen werden sollte. ${ }^{114}$ In diesem Zusammenhang hatte das Foreign Office auch bemerkt, daß die Nichtkernwaffenstaaten nicht zu einem einseitigen Verzicht gedrängt

\footnotetext{
109 Ebenda.

110 PRO, FO 371/187462, Richardson to Stuart, 02. 03. 1966.

111 PRO, FO 371/187462, Street to Richardson, 01. 04. 1966.

112 Seaborg, Tide, S. 364-365.

${ }^{113}$ PRO, FO 371/187470, FO to Brit. Embassy, Washington, 19. 10. 1966.

${ }^{114}$ PRO, FO 371/187470, UK-Mission to UN to FO, 19. 10. 1966.
} 
werden dürften, sondern die Atommächte in jedem Fall einen fairen Ausgleich anbieten müßten. ${ }^{115}$ Dort unterstützte man aber nach wie vor die amerikanische Forderung nach einem Verbot aller Explosionen. Besondere Bedeutung wurde der deutschen Reaktion auf ein Verbot beigemessen. Allerdings ging man in London davon aus, daß die USA die unangenehme Aufgabe übernehmen würden, der Bundesregierung zu erklären, daß eine Unterscheidung zwischen militärischen und zivilen Tests nicht möglich sei. Man wollte sich nicht auch noch in dieser Frage in Bonn unbeliebt machen. ${ }^{116}$

Im März 1967 legten die Vereinigten Staaten einen konkreten Plan vor, wie die Nichtkernwaffenstaaten die Durchführung einer PNE „in Auftrag geben“ könnten: Demnach sollten derartige Explosionen von einer Atommacht und unter internationaler Beobachtung durchgeführt und die Kosten für den Nichtkernwaffenstaat so gering wie möglich gehalten werden. ${ }^{117}$ Die Bedingungen für internationale Zusammenarbeit auf dem Gebiet der friedlichen Explosionen sollten grundsätzlich erweitert und verbessert werden. In den gemeinsamen Vertragsentwürfen vom August 1967 kam dieser Plan in der Präambel zur Sprache, die zentralen Artikel schlossen ein Verbot der friedlichen Explosionen ein. Der Vertragstext enthielt keinen eigenen Artikel über friedliche Explosionen. Dies war den Nichtkernwaffenstaaten zu wenig. Die Mehrheit war zwar gewillt, den amerikanischen Plan grundsätzlich zu akzeptieren, jedoch sollte die Möglichkeit, PNEs von einer Atommacht durchführen zu lassen, fest im Vertrag verankert werden. Die mexikanische Delegation übernahm nun eine führende Rolle bei der Ausarbeitung eines eigenen Artikels, der genau dies zum Inhalt haben sollte. ${ }^{118}$ Bei der Formulierung hielten sich die Mexikaner eng an die Vorgaben des amerikanischen Plans vom März 1967. Die meisten Nichtkernwaffenstaaten unterstützten schließlich den Antrag Mexikos, die mexikanische Formulierung als Artikel V in den Vertragstext aufzunehmen. Nur Indien und Brasilien beharrten auf dem individuellen Recht jedes Staates, friedliche Explosionen selbständig durchführen zu dürfen.

Neben Indien und Brasilien hatte auch Großbritannien gegen den Artikel V gestimmt. Die Briten argumentierten, Großbritannien unterhalte nicht, wie die USA oder die Sowjetunion, ein nationales Programm zur Durchführung friedlicher Explosionen und sehe sich deshalb auch nicht in der Lage, der internationalen Staatengemeinschaft ein entsprechendes Angebot zu machen. Tatsächlich fürchtete die britische Regierung nun offensichtlich durch ein quid pro quo unkalkulierbar hohe Kosten auf sich zukommen, sollten die Atommächte in dieser Frage von den Nichtkernwaffenstaaten in die Pflicht genommen werden können: „[The Article V] could be interpreted as obliging nuclearweapon States to develop a peaceful explosives technology and service for the benefit of others even if they had neither the desire nor the resources to develop such a

115 PRO, FO 371/187465, Street to Richardson, 12. 07. 1966.

${ }^{116}$ Ian Smart von der britischen Botschaft in Washington hatte gefordert, die britische Botschaft in Bonn sollte umgehend Konsultationen mit der Bonner Regierung aufnehmen "to rub in the impossibility of discriminating between peaceful explosive devices and weapons". PRO, FO 371/ 187473, Smart to Street, 18. 11. 1966. Street antwortete jedoch folgendermaßen: „It is not a point on which we need to take a lead in convincing the Germans of its necessity.... We can presumably rely on the Americans to push this strongly." PRO, FO 371/187473, Street to Smart, 25. 11. 1966.

${ }^{117}$ Shaker, Non-Proliferation, S. 381.

${ }^{118}$ Ebenda, S. 382-383. 
service. "119 Die Gegner des Artikels V wurden jedoch überstimmt, und die Supermächte trugen diesem Votum Rechnung, indem sie den von Mexiko formulierten Artikel in den zweiten gemeinsamen Vertragsentwurf aufnahmen, der Anfang des Jahres 1968 vorgelegt wurde. Es sollte sich allerdings zeigen, daß die britischen Befürchtungen unbegründet waren, da die Bedeutung von Atomexplosionen zu friedlichen Zwecken stark überschätzt worden war.

\section{Verpflichtung der Supermächte zu nuklearer Abrüstung}

Im Laufe des Jahres 1965 forderten immer mehr Nichtkernwaffenstaaten, der Nichtverbreitungsvertrag solle mit umfangreichen Abrüstungsmaßnahmen der Supermächte gekoppelt sein. Die radikalsten Forderungen kamen aus der indischen Delegation. Die Inder verlangten, der NPT müsse ein freeze- und ein cut-off-Abkommen enthalten und langfristig zu völliger nuklearen Abrüstung führen. Die Nichtkernwaffenstaaten müßten sich dabei erst dann zum nuklearen Verzicht bereit erklären, wenn die Atommächte die Produktion von weiteren Waffen eingestellt und ihre Arsenale reduziert hätten. ${ }^{120}$ Auch Kanada und Ägypten sprachen sich für einen konkreten Abrüstungsplan innerhalb des NPT aus. ${ }^{121}$ Der italienische Außenminister Fanfani hatte im Juli 1965 ein zeitlich begrenztes Moratorium der Nichtkernwaffenstaaten vorgeschlagen. In dieser Zeit sollten sich die Supermächte auf ein Abrüstungsabkommen einigen. ${ }^{122}$ Schweden wollte zudem baldmöglichst zu einem CTBT kommen. ${ }^{123}$ Die Resolution der Nichtkernwaffenstaaten vom November 1965 verlangte die Aufnahme von Abrüstungsmaßnahmen in den Vertrag. Dies wurde in einem Memorandum der acht blockfreien Staaten der ENDC im August 1966 noch einmal ausdrücklich bestätigt. ${ }^{124}$

Die Nichtkernwaffenstaaten sprachen damit in der Frage der Abrüstungsmaßnahmen eine deutliche Sprache. ${ }^{125}$ Warum sollten sie auf Kernwaffen verzichten, wenn sich dadurch die globale nukleare Bedrohung in keiner Weise verringern würde? Die Supermächte schienen indes nicht bereit, als Gegenleistung für die Verzichtserklärung zumindest eine Reduzierung der eigenen Arsenale vorzunehmen, denn keiner der 1965 vorgelegten Vertragsentwürfe enthielt konkrete Bestimmungen über begleitende Abrüstungsmaßnahmen. Die Resolution der Nichtkernwaffenstaaten bedeutete den Atommächten jedoch unmißverständlich, daß die bisherigen Entwürfe in bezug auf Abrüstungsmaßnahmen völlig unzureichend waren. Die USA hatten zwar ebenso wie die Sowjetunion 1965 einen umfassenden Abrüstungsplan vorgelegt, und die amerikanische Delegation in Genf hatte auch noch einmal Gespräche über einen Produktionsstopp von spaltbarem

119 ENDC/PV. 337, 10. 10. 1967. Rede von Staatsminister Mulley vor der ENDC.

${ }^{120}$ ENDC/PV. 222, 10. 10. 1965.

${ }^{121}$ Ebenda.

${ }^{122}$ Nuti, ,Me too, please', S. 133.

${ }^{123}$ ENDC/PV. 222, 10. 10. 1965.

${ }^{124}$ ENDC/Doc. 178 submitted to ENDC/PV. 284, 23. 08.1966.

${ }^{125}$ Die Verhandlungen um die Sicherheitsgarantien und den Artikel III zeigten, daß die Nichtkernwaffenstaaten keineswegs eine einheitliche Front gegenüber den Atommächten bildeten. In der Frage der Abrüstungsmaßnahmen gab es jedoch einen breiten Konsens für eine Verbindung von Nichtverbreitungsvertrag und Abrüstungsmaßnahmen. 
Material sowie ein Einfrieren bestimmter Waffensysteme angeboten. Das Interesse war jedoch auf beiden Seiten eher mäßig. Vor dem Hintergrund des eskalierenden VietnamKonflikts war keine der Supermächte an Abrüstungsverhandlungen interessiert. Präsident Johnson hatte - abgesehen von den Abrüstungsvorschlägen in seiner Rede vor der ENDC Anfang 1964 - Abrüstungsfragen ohnehin nie besondere Beachtung geschenkt. Die Kreml-Führung gab zu erkennen, daß für sie ein anderes Abkommen als der Nichtverbreitungsvertrag derzeit nicht aktuell war. Aus Moskau verlautete stereotyp, daß wirkliche Abrüstung nur in Form eines umfassenden Abrüstungsplans erfolgen könne. ${ }^{126}$

Die britische Regierung hatte den cut-off nur unter Vorbehalt unterstützt und war immer mehr an einem umfassenden Teststopp-Abkommen interessiert gewesen. Nachdem klar wurde, daß in keinem der konkreten Abrüstungsvorschläge ein Vorankommen zu erwarten war, konzentrierten die Briten ihre ganzen Bemühungen auf den Abschluß eines CTBT. Lord Chalfont drängte schon seit einiger Zeit in Washington immer heftiger darauf, die USA sollten die Bedingung aufgeben, ein CTBT müsse durch eine bestimmte Anzahl von Kontrollen vor Ort überwacht werden. Die Verhandlungen über ein umfassendes Testverbot sollten jedoch separat von den Nichtverbreitungsverhandlungen geführt werden. Auch in der Abrüstungsfrage galt: London wollte den NV-Vertrag so bald wie möglich, daher war man strikt dagegen, Bestimmungen über Abrüstungsmaßnahmen zu einem Bestandteil des Vertrages zu machen. Ein Memoranum des Foreign Office gab für die Verhandlungen in den Vereinten Nationen im Herbst 1965 folgenden Kurs vor: „Her Majesty's Government's attitude is that to tie an agreement on non-dissemination to a package of other disarmament proposals would be to delay and possibly to prevent the acceptance of a Treaty. Her Majesty's Government will continue to work for G.C.D. as well as other collateral disarmament measures. But negotiations on these measures have proved long and difficult, and the need for a non-dissemination agreement is so urgent that it ought not to be held up by any lack of progress in collateral negotiations. "127 Abrüstungspolitik bedeutete für die britische Regierung in der folgenden Zeit, die amerikanische Regierung zur Aufgabe der nuclear-sharing-Pläne zu drängen, um möglichst schnell eine Einigung der Supermächte zu erzielen. Daneben bestand die Notwendigkeit, das Problem der Sicherheitsgarantien zu lösen und die Kontrollfrage nach den britischen Vorstellungen zu regeln, nicht aber Bemühungen, den NP'T zu einem tatsächlichen Abrüstungsabkommen auszubauen. ${ }^{128}$ Unabhängig davon war man nur

126 PRO, PREM 13/1251, Chalfont to FO, 25. 03. 1966 sowie NA, RG 59, CFPF, DEF 18, box 1592, US-Del., Geneva, to Dept of State, 06. 02. 1966. Verhandlungen über G.C.D. fanden jedoch schon seit einiger Zeit nicht mehr statt. Ein ACDA-Memorandum über G.C.D. berichtet: "The Indian representative was not greatly exaggerating when he told the ENDC in 1968 that there had been no negotiations on general and complete disarmament since 1964. Both the United States and the Soviet Union realized that it was fruitless to continue the discussions on general and complete disarmament." NSA, MC, Doc. Nr. 1232, ACDA Memo: The US-Arms-Control and Disarmament Agency During the Johnson-Administration, 04. 11. 1968.

${ }^{127}$ PRO, FO 371/181392, FO-Memo: UN General Assembly 20th Session, Supplementary Brief: Non-Dissemination, September 1965, ohne genaues Datum.

${ }^{128}$ Nachdem im März 1966 die Sowjetunion mit dem Kossygin-Vorschlag beträchtliche Sympathien bei den Nichtkernwaffenstaaten erzielt hatte und keine Einigung zwischen den Supermächten in Aussicht war, überlegte man kurzeitig im Foreign Office, ein westliches Angebot in Form eines kombinierten NPT/freeze/cut-off in Genf vorzulegen, wohlwissend, daß die Sowjetunion dieses 
daran interessiert, die Fortsetzung der Verhandlungen über ein umfassendes Teststoppabkommen als weiteren Damm gegen Proliferation zu forcieren. Im Frühjahr 1966 wurde die amerikanische Regierung davon informiert, daß die Briten nun offiziell die Position verträten, eine Überwachung eines CTBT sei nicht erforderlich. ${ }^{129}$ Dabei spielte es keine Rolle, daß dies innenpolitisch bei den engsten Verbündeten nicht durchsetzbar war.

Während die Atommächte über nukleare Abrüstung sprachen, betrieben verschiedene Nichtkernwaffenstaaten aktive Nichtverbreitungspolitik. So verhandelten die Staaten Mittel- und Südamerikas über einen Vertrag, der die südliche Hälfte des amerikanischen Kontinents zur atomwaffenfreien Zone erklären sollte. Ähnliche Überlegungen gab es in verschiedenen afrikanischen Staaten. Die Atommächte sollten sich verpflichten, diese Zone zu respektieren und den beteiligten Staaten eine nukleare Nichtangriffsgarantie zuzusagen. Die Atommächte reagierten auf dieses Vorhaben positiv. Innerhalb der britischen Regierung war insbesondere Premierminister Wilson von den Plänen begeistert und sprach sich für eine Förderung dieser Bestrebungen vor allem in Afrika aus. ${ }^{130}$ Das britische Verteidigungsministerium machte jedoch Vorbehalte deutlich, da ein solches Abkommen gerade in Afrika eine Einschränkung der britischen Transit- und Überflugrechte zur Folge gehabt hätte. ${ }^{131}$ Nachdem ACDA-Mitarbeiter versicherten, die südamerikanischen Staaten hätten zugesagt, sämtliche Transitrechte zu respektieren, unterstützte die britische Regierung die Schaffung einer kernwaffenfreien Zone in Südamerika vorbehaltlos. Sie sprach sich auch für eine möglichst breite Beteiligung aus, machte aber deutlich, daß sie auch ein Abkommen unterstützen werde, das nur einige wenige Staaten umfasse. ${ }^{132}$ Die britische Regierung unterzeichnete schließlich im Februar 1967 den Vertrag von Tlateloco, der Südamerika für kernwaffenfrei erklärte. Sie unterstützte auch einen Antrag Mexikos, nach dem ein Artikel in den NPT aufgenommen werden sollte, der nichtnuklearen Staatengruppen das Recht zusicherte, sich zu einer kernwaffenfreien Zone zusammenzuschließen. Damit blieb die Option auf ein ähnliches Abkommen in Afrika gewahrt. Mit dem Vertrag von Tlateloco leisteten die nichtnuklearen Staaten Südamerikas schon vor dem Abschluß des NPT einen großen Beitrag zur Verhinderung von Proliferation.

Der erste gemeinsame Vertragstext der USA und der Sowjetunion vom August 1967 nahm wenigstens in der Präambel auf die Abrüstungsfrage Bezug. Außer einer Willenser-

Angebot zurückweisen würde. Der Westen würde damit zwar in der Sache nicht vorankommen, aber einen Propagandaerfolg erzielen und die Sympathien der Nichtkernwaffenstaaten zurückgewinnen. Diese Überlegungen wurden jedoch umgehend wieder fallengelassen. Zum einen bestanden in Großbritannien selbst nach wie vor Bedenken gegen den cut-off, zum anderen kam man zu dem Schluß, daß diese Initiative die eigentlichen Verhandlungen um den NPT möglicherweise ernsthaft gefährden könnte. PRO, FO 371/187463, Street to Beeley, 30. 03. 1966.

${ }_{129}$ PRO, FO 371/187437, FO Position Paper, 17. 05. 1966.

130 PRO, PREM 13/1251, Minute of PM Wilson, 15. 10. 1965.

${ }^{131}$ Großbritannien müsse sich das Recht vorbehalten, bei militärischen Überflügen Geheimhaltung darüber zu wahren, ob Kernwaffen transportiert würden. Damit bestehe die Gefahr, daß Großbritannien sämtliche militärischen Überflugrechte verlieren werde. Ähnliches gelte für die Schifffahrt. PRO, PREM 13/1251, Mr. Hastie-Smith (MOD) to Mr. Wright (Private Secretary to PM), 20. 10. 1965.

${ }^{132}$ LBJL, NSF, Country File: UK, box 209, Memo of Conversation, 12. 10. 1965. NA, RG 59, CFPF, DEF 18, box 1595, 08. 07. 1966. 
klärung, die Abrüstungsverhandlungen fortzusetzen und umfassende nukleare Abrüstung anzustreben, enthielt der Text aber keinerlei Vorgaben zur Reduzierung der nuklearen Waffenarsenale. Dies provozierte eine Fülle von Vorschlägen, die alle zum Ziel hatten, eine Verpflichtung zur Abrüstung in einem eigenen Artikel im Vertrag zu verankern. ${ }^{133}$ Die Supermächte sahen sich daraufhin gezwungen, dem Druck nachzugeben und Zugeständnisse zu machen. Die überarbeitete Fassung vom Januar 1968 enthielt einen Artikel VI, demzufolge alle Staaten verpflichtet waren, weitere Abrüstungsverhandlungen anzustreben. ${ }^{134}$ Die Formulierung "to pursue in good faith" entband die Supermächte freilich von jeglicher Erfolgsverpflichtung in den Verhandlungen. Der sowjetische Delegationsleiter in Genf betonte in einer Rede, daß die Nichtkernwaffenstaaten, sollten sie auf konkreteren Maßnahmen beharren, den NPT zu Fall bringen würden. Die Positionen der Supermächte lägen in der Abrüstungspolitik zu weit auseinander. In dieser Argumentation wurde er von seinem amerikanischen Kollegen unterstützt. Wenn die internationale Staatengemeinschaft diesen Vertrag so nicht akzeptieren könne, erklärten Zarapkin und Fisher, werde es gar keinen Vertrag geben. ${ }^{135}$ Die Sowjetunion drohte außerdem den Staaten, die einem Vertrag fernblieben, die zivile nukleare Hilfe deutlich $\mathrm{zu}$ reduzieren und die Mitgliedstaaten zu bevorzugen. ${ }^{136}$

Die Briten versuchten in dieser Situation, die Nichtkernwaffenstaaten davon zu überzeugen, daß es unrealistisch war, konkrete Abrüstungszusagen von den Supermächten zu fordern. Dies verzögere und gefährde nur den Vertragsabschluß. ${ }^{137}$ Die britische Regierung schlug den Nichtkernwaffenstaaten vor, sie sollten eine Absichtserklärung der USA und der Sowjetunion in bezug auf Abrüstungsverhandlungen akzeptieren. Zugleich könne ein Beschwerderecht in den Vertrag aufgenommen werden, falls die Supermächte in den Verhandlungen keine ernsthaften Bemühungen an den Tag legten. ${ }^{138}$ Diese Lösung stärkte nicht nur die Position der Staaten, die auf Kernwaffen verzichteten, ohne die Supermächte unmittelbar zu binden, sie wurde auch den britischen Interessen in der Abrüstungspolitik gerecht. Der NPT mußte keine weiteren abrüstungspolitischen Hürden mehr nehmen, und die Fortsetzung intensiver Verhandlungen um den CTBT konnte mit dem Beschwerderecht jederzeit angemahnt werden. Konkret sollte alle fünf Jahre eine Konferenz der Unterzeichnerstaaten stattfinden, um sicherzustellen, daß die Zielsetzung des Vertrags von allen Parteien ordnungsgemäß erfüllt werde. Außerdem schlugen die Briten noch einige Änderungen des Artikels VI vor, um hervorzuheben, daß es nicht nur darum ging, daß die Supermächte im Gespräch blieben. ${ }^{139}$ Großbritannien unterstützte auch einen schwedischen Antrag, nach dem in der Präambel auf den TeststoppVertrag von 1963 Bezug genommen werden sollte und die baldige Erweiterung des Vertrags zu einem umfassenden Teststopp-Abkommen als Ziel vorgesehen war. Die Schweden bestanden ferner darauf, daß die Formulierung "at an early date “ in den Artikel VI

${ }^{133}$ Vorschläge kamen unter anderem von Mexiko, Brasilien und Rumänien. Siehe hierzu: Shaker, Non-Proliferation, S. 573-576.

${ }^{134}$ ENDC/Doc. 193 submitted to ENDC/PV. 357, 18. 01.1968.

${ }^{135}$ ENDC/PV. 361, 01. 02. 1968.

${ }^{136}$ New York Herald Tribune, 17. 02. 1968. Die Atommächte hatten in allen Punkten mit viel weniger Widerstand der Nichtkernwaffenstaaten gerechnet. The Guardian, 15. 03. 1967.

137 ENDC/PV. 295, 21. 03. 1967.

${ }^{138}$ ENDC/PV. 337, 10. 10. 1967.

${ }^{139}$ ENDC/Doc. 203 submitted to ENDC/PV. 350, 23.11. 1967. 
eingefügt wurde, um die unmittelbare Fortsetzung der Verhandlungen im Anschluß an die Unterzeichnung des NPT zu gewährleisten. ${ }^{140}$

Schweden vertrat jedoch wie viele andere Staaten auch die Ansicht, daß der Abschluß des Vertrages nun nicht länger durch weitere komplizierte Verhandlungen blockiert werden sollte. ${ }^{141}$ Damit war auch in der Abrüstungsfrage ein Kompromiß erzielt, und der Vertrag konnte im Juli 1968 zur Unterzeichnung vorgelegt werden. Im September 1968 bot die Konferenz der Nichtkernwaffenstaaten diesen noch einmal die Gelegenheit, den Atommächten deutlich zu verstehen zu geben, daß sie sich mit feierlichen Absichtserklärungen nicht zufriedengeben würden und baldige Abrüstungsmaßnahmen dringend erwarteten. Die Abschlußerklärung der Konferenz listete die Maßnahmen auf, die die Nichtkernwaffenstaaten in naher Zukunft verwirklicht sehen wollten. Zunächst sollte ein Verbot der Entwicklung von neuen Waffensystemen bzw. ein Einfrieren der bestehenden Bestände (freeze) erfolgen. Als nächste Schritte wurden der Abschluß des CTBT sowie ein cut-off-Abkommen gefordert. Ein Vertrag über umfassende und vollständige nukleare Abrüstung stellte schließlich das Endziel dar. ${ }^{142}$

\section{Die Verhandlungen über den NPT - eine Bilanz aus britischer Sicht}

Der Vertrag über die Nichtverbreitung von Kernwaffen wurde am 1.Juli 1968 in Washington, Moskau und London unterzeichnet. Mehr als 50 Nichtkernwaffenstaaten leisteten noch an diesem Tag ihren offiziellen Verzicht auf nukleare Waffen. Bis zur Überprüfungskonferenz 1975 traten insgesamt 95 Staaten dem NPT bei. Trotzdem stellte der Nichtverbreitungsvertrag schließlich keinen globalen Damm gegen Proliferation dar, da viele "Schlüsselstaaten“, wie Indien und Pakistan, Israel, Südafrika und Brasilien, den Vertrag nicht unterzeichneten. Gerade diese Staaten, deren Beitritt die internationale Staatengemeinschaft für wesentlich erachtete und der Signalwirkung auf viele Nichtkernwaffenstaaten gehabt hätte, blieben schließlich dem Abkommen fern. Neben vielen atomaren Schwellenländern weigerten sich auch China und Frankreich beizutreten, wobei dies jedoch schon vorher feststand. General de Gaulle festigte damit die Rolle Frankreichs als enfant terrible im westlichen Lager, aber er erklärte immerhin, Frankreich werde sich so verhalten, als ob es den Vertrag unterzeichnet hätte. ${ }^{143}$ Das britische Interesse konzentrierte sich allerdings viel mehr auf die Bundesrepublik und die anderen Verbündeten. Die Gefahr, daß ein atomares Schwellenland heimlich ein primitives Atomprogramm entwickelte, war für die Briten weniger bedeutsam.

Die Bundesregierung war zunächst nicht zu einer Unterzeichnung bereit. Sie bezeichnete den sowjetischen Einmarsch in die Tschechoslowakei als weiteren Grund gegen das Abkommen und fühlte sich in ihren Warnungen vor einem Entgegenkommen gegenüber Moskau zutiefst bestätigt. Die Kreml-Führung erklärte in dieser Situation, daß die Sowjetunion gemäß den Feindstaatklauseln 53 und 107 der Charta der Vereinten Nationen ein Recht habe, sich in die inneren Angelegenheiten der Bundesrepublik einzumischen,

\footnotetext{
${ }^{140}$ ENDC/Doc. 215 submitted to ENDC/PV. 364, 13.02. 1968.

141 ENDC/PV. 363, 20. 02. 1968.

142 EA 23 (1968) 21, S. D 544-545, 29. 09. 1968.

${ }^{143}$ EA 23 (1968) 19, S. D 332, 01.07. 1968.
} 
falls sich die Bundesrepublik provokativ verhalte. Die Regierung in Bonn verlangte daraufhin Garantien gegen eine sowjetische Intervention, bevor sie das Abkommen unterzeichnete. Hinzu kam, daß die Kreml-Führung ein Inkrafttreten des Vertrages von der deutschen Unterschrift abhängig machte. Durch die abwartende Haltung Moskaus entstand der Eindruck, daß die Sowjetunion den Vertrag ausschließlich als Mittel betrachtete, um die Bundesrepublik Deutschland zu kontrollieren. Bonn machte aus diesem Grund auch die Ratifikation in Moskau zu einer Vorbedingung für ihren Beitritt. ${ }^{144}$ In den USA ließ der neue Präsident Nixon die Ratifizierung des Abkommens aufgrund der sowjetischen Aggression zunächst auf unbestimmte Zeit verschieben. Damit verringerte sich auch der amerikanische Druck auf Bonn, dem Vertrag beizutreten. ${ }^{145}$ In dieser Situation hatte Großbritannien wenig Einfluß auf das Geschehen. Dabei kam gerade zu diesem Zeitpunkt ein Aspekt hinzu, der die Unterzeichnung der Bundesrepublik für Großbritannien noch wichtiger erschienen ließ. Seit 1968 gabe es Pläne für den Bau einer deutsch-niederländisch-britischen Isotopentrennanlage. Nachdem das Projekt bekannt worden war, mußte Großbritannien auch international erhobene Vorwürfe abwehren, die Briten verschafften den Deutschen Zugang zu Atombomben. ${ }^{146}$ Die Regierung in London konnte jedoch nur darauf hoffen, daß sich die Lage entspannte. Der bundesdeutsche Beitritt wurde erst möglich, als die Kreml-Führung der Bundesrepublik in der Frage des Interventionsverzichts einen Schritt entgegenkam und die Supermächte schließlich eine gleichzeitige Ratifizierung beschlossen. Die sowjetische Führung überreichte in Bonn eine Erklärung, in der die Einbeziehung der Bundesrepublik Deutschland in die Resolution der Vereinten Nationen zum Schutz der Nichtkernwaffenstaaten ausdrücklich bestätigt wurde. ${ }^{147}$ Washington und Moskau einigten sich im Herbst 1969 darauf, den Vertrag so bald wie möglich in Kraft treten zu lassen. Unmittelbar nach dieser Erklärung unterzeichnete Bundesaußenminister Brandt am 28. November 1969 den Vertrag. ${ }^{148}$ Die übrigen europäischen Verbündeten waren unterdessen ebenfalls beigetreten. Die Aussicht, daß die Bundesrepublik oder ein anderer NATO-Partner eine Kontrollbefugnis über Kernwaffen erhalten könnte, war damit in weite Ferne gerückt.

Die Bundesrepublik hatte auf Dauer auf den Besitz von Atomwaffen verzichtet, Großbritannien konnte die unabhängige Nuklearmacht nicht nur behalten, sondern sogar jederzeit erweitern. Der Nichtverbreitungsvertrag verbot nur die horizontale, nicht aber die vertikale Proliferation. Die nukleare special relationship, der Vertrag von Nassau und alle zukünftigen Waffenkäufe in den USA waren von dem Abkommen in keiner Weise betroffen. Eine Beschränkung der Waffentransfers unter Atommächten hatte während der Verhandlungen überhaupt keine Rolle gespielt. Gleichzeitig unterstrich der Vertrag indirekt die anglo-amerikanische Führung im westlichen Verteidigungsbündnis. Damit schien Großbritannien zunächst alle wesentlichen Ziele erreicht zu haben: den Briten war es gelungen, einen offziell anerkannten, exklusiven Klub der Atommächte zu schaf-

\footnotetext{
${ }^{144}$ Quester, Politics, S. 169.

${ }^{145}$ Hersh behauptet, die Nixon-Regierung hätte jeglichen Druck auf die Bundesregierung, dem Vertrag beizutreten, beendet und nur öffentlich weiterhin für eine bundesdeutsche Unterzeichnung plädiert. Hersh, Samson Option, S. 209-210.

${ }^{146}$ The Times, 23. 01. 1969.

${ }^{147}$ Küntzel, Bonn, S. 193.

${ }^{148}$ Zur Bonner NPT-Politik nach der Unterzeichnung des Abkommens bis zur deutschen Unterschrift siehe: Küntzel, Bonn, S. 189-205.
} 
fen. Der Statusunterschied zwischen Großbritannien und der Bundesrepublik Deutschland war ebenso garantiert wie der Fortbestand der unabhängigen britischen $\mathrm{Ab}$ schreckung. Daraus resultiert die Frage, ob sich die Durchsetzung dieser Ziele für Großbritannien auch langfristig gelohnt hat.

Schon während der Verhandlungen um den Vertrag zeichnete sich ab, daß Großbritannien die Kosten zur Erhaltung der unabhängigen Nuklearstreitmacht kaum noch tragen konnte. Im technologischen Wettlauf mit den Supermächten hatten die Briten den Anschluß längst verloren. Die Zeitschrift Economist veröffentlichte im Dezember 1966 einen Beitrag über mögliche Pläne der Supermächte, Raketenabwehrsysteme zu stationieren. Der Artikel befaßte sich vor allem mit den Auswirkungen dieser neuen Generation von Atomwaffen auf die Glaubwürdigkeit der britischen Abschreckung: „Russia and America are embarked on another round of technological rivalry. This has an important consequence for the rest of the world. This new round widens still further the gap between the strategic capabilities of Russia and America and those of second-class nuclear powers. In the future, these ultra-sophisticated gadgets ... are likely to be the mark of first-class membership of the nuclear club. In that case ... the British deterrent will be to deter other second-class powers. It will be no good for the big league. "149 Im Februar 1967 führte eine vorgesehene Erhöhung des Verteidigungshaushalts um 8,5\% zu einer Regierungskrise. Daraufhin mußte Verteidigungsminister Healey den geplanten Kauf von amerikanischen Poseidon-Raketen stornieren. ${ }^{150}$ Gleichzeitig plante der Verteidigungsminister, die britischen Truppen aus dem Persischen Golf, Malaysia und Singapur bis 1971 nahezu vollständig abzuziehen. ${ }^{151} 1973$ sah sich die britische Regierung gezwungen, ein Angebot der USA, Trident- oder Poseidon-Raketen zu kaufen, aus finanziellen Gründen abzulehnen. Anfang der siebziger Jahre hatte die unabhängige britische $\mathrm{Ab}$ schreckung nicht nur ihre militärische Glaubwürdigkeit, sondern auch ihren Symbolwert als Ausdruck nationaler Größe verloren.

Der Nichtverbreitungsvertrag war für Großbritannien auch ein Mittel, um die Vorrangstellung gegenüber den europäischen NATO-Mitgliedern und die anglo-amerikanische special relationship zu bestätigen. Allerdings hatte die special relationship während der Verhandlungen erheblich gelitten. Die britische Politik zeugte nicht von diplomatischem Geschick und hinterließ in Washington mehrfach den unangenehmen Eindruck, London versuche die amerikanische Nichtverbreitungspolitik zu diktieren. Davon abgesehen hätte es die amerikanische Regierung gerne gesehen, wenn die Briten den NPT zum Anlaß genommen hätten, ihr Atomwaffenarsenal aufzugeben. Gerade mit Blick auf die Bundesrepublik hatte die Regierung in Washington versucht, die Briten für eine schrittweise Einebnung des Status statt einer Zementierung des Unterschieds zu gewinnen. Der Verzicht auf den nuklearen Status hätte es für die Mittelmächte, die sich mit Großbritannien gleichwertig fühlten, wie Deutschland, Italien, Schweden oder Japan, leichter gemacht, den NPT zu akzeptieren. Zugleich drängten die USA auf einen baldigen britischen EG-Beitritt und drückten die Hoffnung aus, daß die Briten nach einer Aufnahme in die EG die unabhängige Atomstreitmacht aufgeben würden. ${ }^{152}$ Großbritan-

\footnotetext{
149 The Economist, 17. 12. 1966.

150 The Times, 17.02.1967 und The Guardian, 09.03.1967.

${ }^{151}$ Carver, Tightrope Walking, S. 77-80.

${ }^{152}$ LBJL, NSF, Subject File: NPT, box 26, Memo by the Dept of State, 06. 04. 1967.
} 
nien und die Vereinigten Staaten verbanden mit der Unterzeichnung des NPT in bezug auf die Folgen für Großbritannien gegensätzliche Erwartungen. In Washington hoffte man, Großbritannien werde sich unter die europäischen Mittelmächte einreihen und die Rolle als zweitklassige Nuklearmacht aufgeben. Genau dies wollten die Briten mit dem Vertrag verhindern.

Die special relationship erhielt nach dem Abschluß des NPT keinen neuen Auftrieb. Nixon propagierte eine "neue Partnerschaft" zwischen Europa und den USA. Im wesentlichen war damit gemeint, daß ein geeintes Europa ein größeres Maß an Eigenverantwortung in der Verteidigungspolitik übernehmen und die zweite Säule im westlichen Bündnis bilden sollte. Für eine anglo-amerikanische Führung war in dieser Konzeption kein Platz. Die Nixon-Regierung drängte damit zwar nicht weiter auf die Aufgabe des britischen Atomwaffenarsenals, aber stellte nun nicht nur die special relationship, sondern auch die nukleare special relationship zu Großbritannien in Frage. Sie suchte eine special relationship mit der Europäischen Gemeinschaft, vor allem mit der Führungsnation der Gemeinschaft der Sechs. Mit dem Ende der Regierung de Gaulles wurde Frankreich als Bündnispartner wiederentdeckt, der eine eigenverantwortliche Verteidigungspolitik für Europa verfolgte. Melandri schreibt, die USA erweckten den Eindruck, Sonderbeziehungen mit Frankreich anzustreben. ${ }^{153}$ Damit nicht genug, boten Nixon und Kissinger Pompidou Anfang der siebziger Jahre nukleare Hilfe an und beteuerten, in der Nuklearpolitik gegenüber Frankreich habe sich die Situation um hundertachtzig Grad gewandelt. ${ }^{154}$ Die USA waren grundsätzlich nicht länger bereit, den Briten preferential treatment zu gewähren, obwohl die Offerte an Frankreich zunächst am McMabon-Act und dem tiefverwurzelten französischen Mißtrauen scheiterte. ${ }^{155} \mathrm{Im}$ Hinblick auf die Außenpolitik der Europäer sollte sich das amerikanische Interesse in der folgenden Zeit hauptsächlich auf die Ostpolitik der Bundesrepublik Deutschland konzentrieren. Auch auf britischer Seite relativierte sich schließlich mit der Aufnahme in die Europäische Gemeinschaft 1971 das Interesse an der special relationship. ${ }^{156}$

Im Dezember 1967 verkündete General de Gaulle zum zweiten Mal sein Veto gegen den britischen Beitritt zur Gemeinschaft der Sechs. Das Nein des Generals war zwar erwartet worden, allerdings wäre diese Position innerhalb der Gemeinschaft nur schwer durchsetzbar gewesen, wenn sich Deutschland, Italien und die Benelux-Staaten nachdrücklicher für einen Beitritt Großbritanniens eingesetzt hätten. Von offizieller Seite war man zwar bemüht, einen Zusammenhang zwischen den Verhandlungen in Genf und in Brüssel stets zu verneinen, aber es tauchten immer wieder Vermutungen auf, daß die Regierung in Bonn gute Gründe habe, dem britischen Beitrittsgesuch mit Zurückhaltung zu begegnen. ${ }^{157}$ In der Bundesrepublik war zumindest eine bestimmte Gereiztheit

${ }^{153}$ Melandri, Origines, S. 236.

${ }^{154}$ Ebenda, S. 247.

155 Ebenda, S. 250-255.

${ }^{156}$ Bartlett, Special Relationship, S. 129.

${ }^{157}$ Die Labour-Regierung leistete sich noch weitere diplomatische Verfehlungen. Außenminister Brown verscherzte sich mit Äußerungen über eine baldige Anerkennung der Oder-Neiße-Linie als endgültige Grenze viele Symathien. Die zahlreichen anti-deutschen Âußerungen des sowjetischen Premiers Kossygin während dessen Besuch in London blieben weitgehend unwidersprochen. Siehe u. a. The Times, 15. 02. 1967. Der Guardian mutmaßte, daß die deutsche Abneigung gegenüber Lord Chalfont wegen seines Verhaltens in Genf ein Grund für die mangelnde Bereit- 
gegenüber dem britischen Verhalten zu spüren. ${ }^{158}$ Wenn sich die Briten in Genf zum Fürsprecher der europäischen Belange gemacht hätten, wären die Europäer eher bereit gewesen, das britische Anliegen in Brüssel nachdrücklich zu unterstützen und die Konfrontation mit de Gaulle zu riskieren. So aber hatte insbesondere die Bundesrepublik Deutschland keinen Grund, sich für Großbritannien einzusetzen und die guten Beziehungen zu Frankreich aufs Spiel zu setzen. ${ }^{159}$ Selbst in Großbritannien wurde die britische Haltung gegenüber den Europäern als kurzsichtig und europafeindlich verurteilt. Die britische Wochenzeitschrift Spectator fällte ein vernichtendes Urteil: „The Government's conduct over the non-proliferation treaty at a time when it is ostensibly seeking membership of the Common Market and in particular, Italian and German help in gaining it - represents one of the most inept episodes in the annals of British diplomacy. " 160

Die nukleare special relationship erwies sich als nicht mehr finanzierbar, die Aufnahme in das europäische Haus war gescheitert. Eine gemeinsame europäische nukleare Verteidigungspolitik hatte die britische Regierung strikt abgelehnt. Mit dem NPT war andererseits nichts gewonnen. Was hätte eine Verzögerung oder ein Scheitern des Vertrages für Großbritannien bedeutet? Der nukleare Statusunterschied zu den übrigen NATO-Verbündeten wäre auch ohne den NPT nicht vollständig eingeebnet worden. Welche Atommacht wäre bereit gewesen, Kernwaffen an Deutschland weiterzugeben? Die nukleare NATO-Flotte war in Washington längst begraben. Selbst wenn in ferner Zukunft eine MLF realisiert worden wäre, hätte Großbritannien das Recht gehabt, seine nukleare Flotte jederzeit abzuziehen und unter nationale Kontrolle zu stellen. Außerdem hätte eine MLF niemals „einen deutschen Finger am nuklearen Abzugshahn“ bedeutet, wie der britsche Premierminister sich - sehr zum Mißfallen der Bundesregierung - auszudrücken pflegte. ${ }^{161}$

Die britische Regierung versuchte zwar die Tradition des top table der internationalen Abrüstungsverhandlungen aufrechtzuerhalten und legte unmittelbar nach Abschluß des Nichtverbreitungsvertrages einen Plan zur Ausarbeitung eines umfassenden TeststoppVertrages vor. Überdies forderte sie, die geltenden Bestimmungen über die Ächtung von

schaft der Deutschen gewesen sei, sich für Großbritannien zu engagieren. The Guardian, 21. 02. 1968. Kiesinger und Brandt waren während Wilsons Besuch in Bonn tatsächlich eher zurückhaltend. Beide versprachen zwar, in Paris für den britischen Beitritt zu werben, aber machten auch klar, daß Bonn das britische Beitrittsgesuch nicht enthusiastisch unterstützen werde - mit dem Argument, dies würde de Gaulle nur noch stärker gegen den britischen Beitritt aufbringen. PRO, PREM, 13/1478, Memo of Conversation, 16. 02. 1967.

${ }^{158}$ Der Kommentator der FAZ, Heinz Höpfl, schrieb: „Angesichts des Hochmuts der nuklearen Supermächte, die für die Erhaltung ihrer Hegemonie nur von den anderen, nicht von sich selbst $\mathrm{Op}^{-}$ fer fordern, hätte Großbritannien sich und seiner europäischen Sache besser gedient, wenn es sich als mittlere, aber nukleare Macht zum Anwalt der Bedenken und Sorgen der Habenichtse gemacht hätte." FAZ, 02.03. 1967.

${ }^{159}$ Kiesinger machte in den Gesprächen mit Wilson und Brown explizit deutlich, daß er wegen der unterschiedlichen Ansichten in Bonn und Paris bezüglich des britischen EG-Beitritts keinen Krach mit de Gaulle riskieren werde. PRO, PREM 13/1478, Memo of Conversation, 15. 02. 1967.

${ }^{160}$ The Spectator, 24. 02. 1967.

${ }^{161}$ Im Auswärtigen Amt wurde dazu bemerkt: „Wir halten diese bildhafte Beschreibung der nuklearen Verfügungsgewalt in keinem Falle für glücklich... . Es wird vorgeschlagen, der Herr Bundeskanzler möge den britischen Premierminister ... darauf hinweisen, wie wichtig es im Interesse aller Allianzpartner ist, daß ihre Verteidigungspolitik der Öffentlichkeit in unangreifbarer Weise dargestellt wird." AdAA, Ref. 2, B 1, Bd. 972, Aufzeichnung von MD Werz, 16. 05. 1966. 
bakteriologischen und chemischen Waffen zu verschärfen. Vom Abschluß des NPT gingen jedoch keine entscheidenden Impulse für weitere Abrüstungsverhandlungen aus. Die Supermächte hatten sich unabhängig von den NPT-Verhandlungen im März 1967 auf bilaterale Gespräche zur Begrenzung von Raketenabwehrsystemen und strategischen Atomwaffen verständigt. ${ }^{162}$ Mit dem Aufkommen von Raketenabwehrsystemen drohte erneut eine Destabilisierung der Abschreckungsbalance und die Gefahr einer nuklearen Eskalation. Auch angesichts der Situation in Vietnam waren bilaterale Verständigung und Entspannung wichtigstes Ziel der Supermächte geworden. Für Großbritannien war in diesen Verhandlungen kein Platz. In London mußte man von nun an gemeinsam mit den übrigen westeuropäischen Regierungen darauf achten, daß die USA im Zuge der Entspannungspolitik die strategischen Interessen der Europäer nicht einer Verständigung mit der Sowjetunion opferten. Gleichzeitig mußten die Briten erkennen, daß die Bundesrepublik Deutschland mit der Ostpolitik der sozialliberalen Koalition als Akteur ins Rampenlicht der internationalen Politik rückte. Die Bundesrepublik saß damit nicht am top table, aber sie zeigte, daß erfolgreiche, engagierte Außenpolitik internationalen Prestigegewinn nach sich zog, der nicht an Kernwaffenbesitz gebunden war.

Zusammenfassend läßt sich damit folgendes Fazit ziehen: Großbritannien strebte nach einem international anerkannten, letztlich aber doch bedeutungslosen Sonderstatus, der die Stellung als Großmacht zu garantieren schien. Großbritannien hatte durch diesen Sonderstatus, für den sowohl eine konservative als auch eine Labour-Regierung so erbittert gekämpft hatten, jedoch nichts gewonnen. Der Spectator bezeichnete den Nichtverbreitungsvertrag treffend als „worthless triumph“ für Großbritannien. ${ }^{163}$

${ }^{162}$ Zur Geschichte der SALT-Verträge siehe: Smith, Doubletalk.

${ }^{163}$ The Spectator, 24. 02. 1967. 
